\title{
Work Groups and Teams in Organizations
}

\author{
Steve W. J. Kozlowski \& Bradford S. Bell \\ Michigan State University
}

First Draft: 4 January 2001

Final Draft: 1 May 2001

Final Submission: 18 July 2001

\section{Citation:}

Kozlowski, S. W. J., \& Bell, B. S. (2003). Work groups and teams in organizations. In W. C. Borman, D. R. Ilgen, \& R. J. Klimoski (Eds.), Handbook of psychology (Vol. 12): Industrial and Organizational Psychology (pp. 333-375). New York: Wiley.

Author affiliations: Steve W. J. Kozlowski, Department of Psychology, Michigan State University, and Bradford S. Bell, Department of Psychology, Michigan State University. Correspondence should be sent to: Steve W. J. Kozlowski, Department of Psychology, Michigan State University, East Lansing, MI 48824-1117; Voice: 517-353-8924; Fax: 517-353-4873; E-mail: stevekoz@msu.edu.

We would like to acknowledge several colleagues who provided insightful comments on an initial outline or draft of this chapter. Our thanks to Neil Anderson, Murray Barrick, Jan Cannon-Bowers, Paul Goodman, Stan Gully, Cyn D. Fisher, Richard Hackman, John Hollenbeck, Susan Jackson, Michelle Marks, John Mathieu, Susan Mohamed, Greg Stewart, Anne Tsui, Eduardo Salas, Ruth Wageman, Wang Zhong-Ming, and Michael West. Thanks also to Richard Klimoski for his helpful editorial guidance throughout. We would also like to acknowledge the Air Force Office of Scientific Research for support (F49620-98-1-0363 and F49620-01-1-0283, S.W.J. Kozlowski and R.P. DeShon, Principal Investigators) that in part assisted the composition of this chapter. Although many sources provided inputs to this chapter, the views expressed are those of the authors. 
THE NATURE OF WORK TEAMS AND GROUPS

What Is a Team?

Types of Work Teams

General Typologies.

More Specific Classifications.

The Role of Typology in Understanding Teams.

TEAM COMPOSITION

$\underline{\text { Team Size }}$

Diversity

Personality

Ability

Theoretical and Empirical Issues

Applied Issues

TEAM FORMATION, SOCIALIZATION, AND DEVELOPMENT

Formation

Socialization

Group and Team Socialization.

Direct Findings for Work Group Socialization.

Indirect Findings for Work Group Socialization.

Role of the Group in Socialization.

Development

Classic Stage Models.

Implications for Work Team Development.

$\underline{\text { Research Implications and Application Issues }}$

Socialization.

Development.

TEAM EFFECTIVENESS, PROCESSES, AND ENHANCEMENTS

Team Effectiveness

$\underline{\text { Team Processes }}$

Cognitive Constructs and Mechanisms.

Affective and Motivational Constructs and Mechanisms. 
Behavioral Constructs and Mechanisms.

Enhancing Team Effectiveness

Decision Effectiveness.

Team Competencies and Performance.

Team Training.

Issues for Future Research on Team Training.

\section{TEAM LEADERSHIP AND MOTIVATION}

Team Leadership

Functional Role of Team Leaders.

Self-Managing Teams.

Practical Applications.

Team Motivation

Productivity Loss.

Theories of Team Motivation.

Practical Recommendations.

CONTINUANCE AND DECLINE

Team Viability

$\underline{\text { Recommendations for Enhancing Team Viability. }}$

\section{RESEARCH ISSUES AND RECOMMENDATIONS}

$\underline{\text { Research Issues }}$

Context.

Task Interdependence.

Levels.

Time.

$\underline{\text { Research Recommendations }}$

The Nature of Teams.

Composition.

Formation, Socialization, and Development.

Team Effectiveness, Processes, and Enhancements.

Leadership and Motivation.

Continuance and Decline.

Conclusion 
The last decade and a half has witnessed a remarkable transformation of organizational structures worldwide. Although there are economic, strategic, and technological imperatives driving this transformation, one of its more compelling aspects has been an ongoing shift from work organized around individual jobs to team-based work structures (Lawler, Mohrman, \& Ledford, 1995). Increasing global competition, consolidation, and innovation create pressures that are influencing the emergence of teams as basic building blocks of organizations. These pressures drive a need for diverse skills, expertise, and experience. They necessitate more rapid, flexible, and adaptive responses. Teams enable these characteristics. In addition, organizations have globalized operations through expansion, mergers and acquisitions, and joint ventures placing increased importance on cross-cultural and mixed culture teams. Advanced computer and communication technologies provide new tools to better link individuals with their team in real-time, and even enable teams to be virtual-distributed in time and space.

This ongoing transformation in the basic organization of work has captured the attention of researchers and is reflected by new theories of team functioning, a rapidly growing number of empirical studies, and numerous literature reviews written on the burgeoning research on teams. It is also reflected in a shift in the locus of team research. For most of its history, small group research has been centered in social psychology (McGrath, 1997). Over the last 15 years, however, group and team research has become increasingly centered in the fields of organizational psychology and organizational behavior. Indeed, Levine and Moreland (1990) in their extensive review of small group research concluded that, "Groups are alive and well, but living elsewhere.... The torch has been passed to (or, more accurately, picked up by) colleagues in other disciplines, particularly organizational psychology" (p. 620).

Several literature reviews published over the last 15 years help to document this shift in locus, characterize differences brought to group and team research by an organizational perspective, and provide a fairly comprehensive assessment this vast body of research. Goodman, Ravlin, and Schminke (1987) sent a signal marking the shift in locus and highlighted one of the key distinctions between the small group literature, which pays relatively little attention to the group task and its technology, and the organizational literature, which views what groups do and how they do it as a critical characteristics. Similarly, Bettenhausen (1991) documented the emphasis in organizational research on task driven processes in teams, relative to the small group focus on interpersonal attraction and interaction. Sundstrom, De Meuse, and Futrell (1990) presented an organizational systems perspective on teams that addressed both development and effectiveness; two issues rarely considered in concert. Hackman (1992) viewed groups as contexts for individual behavior, an important perspective because teams in part enact 
their context. Guzzo and Shea (1992) and Guzzo and Dickson (1996) reviewed team research in organizations. Cohen and Bailey (1997) and Sundstrom, McIntyre, Halfhill, and Richards (2000) provided focused reviews of work team effectiveness based on field research during the periods of 19901996 and 1980 to mid-1999, respectively. Finally, Gully (2000) presented an insightful assessment of team effectiveness research since 1985 that examines key boundary conditions. An examination of this body of work leads to the conclusion that there is an enormous wealth of information available on work teams in organizations. Nevertheless, answers to many fundamental questions remain elusive.

Our objective in this chapter is to provide an integrative perspective on work groups and teams in organizations, one that addresses primary foci of theory and research, highlights applied implications, and identifies key issues in need of research attention and resolution. Given the volume of existing reviews, our review is not intended to be exhaustive. Rather, it uses representative work to characterize key topics, and focuses on recent work that breaks new ground to help move theory and research forward. Although our approach risks trading breadth for depth, we believe that there is much value in taking a more integrative view of the important areas of team research, identifying key research themes, and linking the themes and disparate topics closer together. To the extent that we identify new and necessary areas of theory development and research, the value of this approach will be evident.

The chapter is organized as follows. We begin by examining the nature of work teams. We define them, identify four critical conceptual issues - context, workflow, levels, and time-that serve as review themes, and discuss the multitude of forms that teams may assume. We then shift attention to the heart of the review, examining key aspects of the creation, development, operation, and management of work teams. To accomplish our objectives of breadth and integration, we adopt a lifecycle perspective to organize the review. Topics involved in the team lifecycle include: (1) team composition; (2) team formation, socialization, and development; (3) team processes and effectiveness; (4) team leadership and motivation; (5) and team continuance and decline. We characterize representative theory and research, identify thematic limitations, and highlight work that is beginning to push the boundaries on critical conceptual issues. We also address application concerns where possible. Finally, we close with a discussion that reflects back on the topics, considers the state of progress regarding our critical conceptual themes, and suggests directions for new research to foster continued progress and development.

\section{THE NATURE OF WORK TEAMS AND GROUPS}

\section{What Is a Team?}

Although some scholars distinguish work teams and work groups (Katzenbach \& Smith, 1993), 
we make no such distinction and use the terms interchangeably. Others distinguish dyads or triads from larger teams. Although we acknowledge that intra-team processes increase in complexity with more team members, we do not highlight these distinctions in this chapter. Work teams and groups come in a variety of types and sizes, cutting across different contexts, functions, internal processes, and external linkages. However, several features provide a foundation for a basic definition. Work teams and groups: (a) are composed of two or more individuals, (b) who exist to perform organizationally relevant tasks, (c) share one or more common goals, (d) interact socially, (e) exhibit task interdependencies (i.e., workflow, goals, outcomes), (f) maintain and manage boundaries, and (g) are embedded in an organizational context that sets boundaries, constrains the team, and influences exchanges with other units in the broader entity (Alderfer, 1977; Hackman, 1987; Hollenbeck, Ilgen, Sego, Hedlund, Major, \& Phillips, 1995; Kozlowski, Gully, McHugh, Salas, \& Cannon-Bowers, 1996a; Kozlowski, Gully, Nason, \& Smith, 1999; Salas, Dickinson, Converse, \& Tannenbaum, 1992).

We view teams from an organizational systems perspective. Teams are embedded in an open yet bounded system composed of multiple levels. This broader system sets top-down constraints on team functioning. Simultaneously, team responses are complex bottom-up phenomena that emerge over time from individual cognition, affect, behavior, and interactions among members within the team context (Kozlowski \& Klein, 2000). Based on this perspective, we assert that four conceptual issues are critical in efforts to investigate and understand work teams: (1) task or workflow interdependence, (2) contextual creation and constraint, (3) multilevel influences, and (4) temporal dynamics. We briefly introduce these issues below and use them as a basis to identify both the strengths and limitations of extant research.

The centrality of task interdependence is one issue that clearly distinguishes the work teams and small group literatures (Goodman et al., 1987). In the organizational literature, technology, and the tasks it entails, denotes the means by which system inputs are transformed or converted to outputs; technology is not equipment or support systems (e.g., McGrath \& Hollingshead, 1994). Technology and its associated tasks create a structure that determines the flow of work and linkage across team members. Interactions among work team members are substantially influenced by this workflow structure (Steiner, 1972; Van de Ven, Delbecq, \& Koenig, 1976), which links individual inputs, outcomes, and goals. Thus, it has a critical influence on team processes essential to team effectiveness. In contrast, laboratory tasks in small group research are often pooled or additive, thereby minimizing the necessity for task-driven interaction among team members (McGrath, 1997). From an organizational systems perspective, the task workflow sets interaction requirements and constraints that must be considered in team theory, research, and practice. 
Teams are embedded in an organizational context and the team itself enacts a context for team members. The broader organizational context characterized by technology, structure, leadership, culture, and climate constrains teams and influences their responses. However, teams also represent a proximal context for the individuals who compose them. Team members operate in a bounded interactive context that they in part create by virtue of their attributes, interactions, and responses. Team-level normative expectations, shared perceptions, and compatible knowledge are generated by and emerge from individual interactions. Dynamic team processes in part create contextual structure that constrains subsequent team processes. Thus, the team context is a joint product of both top-down and bottom-up influences.

Organizations, teams, and individuals are bound together in a multilevel system. Teams don't behave, individuals do; but they do so in ways that create team level phenomena. Individuals are nested within teams, and teams in turn are linked to and nested in a larger multilevel system. This hierarchical nesting and coupling, which is characteristic of organizational systems, necessitates the use of multiple levels - individual, team, and the higher-level context — in efforts to understand and investigate team phenomena. However, many of the theoretical, measurement, and data analytic issues relevant to a multilevel perspective on teams are often neglected in research and practice. These issues are especially important when researchers try to attribute individual characteristics to the team collective (e.g., team ability, team personality, team learning). Such generalizations necessitate precise multilevel theory and analyses to ensure the meaningfulness of the collective team-level constructs (Kozlowski \& Klein, 2000). Unfortunately, there are many examples of such generalizations that lack the standing of true constructs.

Finally, time is an important characteristic of work teams (McGrath, 1990). Teams have a developmental lifespan; they form, mature, and evolve over time (Morgan, Salas, \& Glickman, 1993). Team constructs and phenomena are not static. Many, indeed, most team level phenomena (e.g., collective efficacy, mental models, performance) emerge upwards from the individual to the team level and unfold via complex temporal dynamics (Kozlowski et al., 1999) that include not only linear, but also cyclical, and episodic aspects (Kozlowski et al., 1996a; Marks, Mathieu, \& Zaccaro, 2001). Although time is explicitly recognized in models of team development, it is largely neglected in many other areas of team research; yet time is relevant to virtually all team phenomena. It is impossible to understand team effectiveness without paying attention to the processes that unfold over time to yield it.

\section{Types of Work Teams}

Work teams can assume a wide variety of different forms - they are not unitary entities. Many factors or contingencies relevant to effective team functioning vary across different types of teams, 
creating challenges for studying and understanding them. This fact is reflected in the many efforts to describe, classify, or otherwise distinguish differences among of teams. We consider some of the major distinctions below and then comment on their theoretical and research value.

General Typologies. General typologies are an effort to distinguish a broad range of team types. For example, Sundstrom and colleagues (2000) integrated the Sundstrom et al. (1990) and Cohen and Bailey (1997) typologies to yield six team categories: (1) production, (2) service, (3) management, (4) project, (5) action and performing, and (6) advisory. Production teams represent core employees who cyclically produce tangible products (e.g., automobile assembly) and vary on discretion from supervisorled to semi-autonomous to self-directed. Service teams engage in repeated transactions with customers (e.g., airline attendants) who have different needs, making the nature of the transactions variable. Senior managers of meaningful business units with primary responsibility for directing and coordinating lower level units under their authority comprise management teams. Project teams are temporary entities that execute specialized time-constrained tasks and then disband (e.g., new product development). Action and performing teams are composed of interdependent experts who engage in complex time-constrained performance events. Examples include aircrews, surgical teams, military units, and musicians.

More Specific Classifications. In addition to general typologies, researchers have identified more specific types of teams. For example, some scholars have distinguished crews from other types of work teams (e.g., Cannon-Bowers, Salas, \& Blickensderfer, 1998). The key distinguishing characteristic is the capability and necessity for crews to form and be immediately prepared to perform together effectively (Ginnett, 1993). Thus, advocates of this distinction assert that crews, unlike more conventional teams, do not go through an identifiable developmental process (Arrow, 1998). Examples include aircrews, military combat units, and surgical teams. However, it is notable that crews are used for team tasks that necessitate high expertise, extensive training, and well-developed, standardized performance guidelines. Thus, while crews continually form, disband, and reform with new members as an integral part of their lifecycle, the high level of prior socialization, trained knowledge, and explicit performance standards provide strong structural supports that substitute for an extended group development process.

Top management teams (TMT; Hambrick \& Mason, 1984; Jackson, 1992a) represent another specific classification, one based on level in the organizational hierarchy. Because it is difficult to gain access to TMTs, much of the research on TMT effectiveness has focused on factors that can be gleaned through archival records. As a result, research has centered on TMT composition (e.g., heterogeneity of function, organizational tenure, team tenure, age, and education; team size) and the external environment 
(e.g., industry as a proxy for environmental turbulence, market characteristics), and their effects on organizational effectiveness (Eisenhardt \& Schoonhoven, 1990; Finkelstein \& Hambrick, 1990; Simons, Pelled, \& Smith, 1999; Smith et al., 1994; West \& Anderson, 1996). Although the amount of empirical work in this area is relatively small compared to work team research in general, the area is active and growing. One troubling aspect of this growing area, however, is its relative independence of the broader work teams literature (Cohen \& Bailey, 1997). This is a neglected issue in need of rectification.

More recently, the globalization of organizations and changing nature of work have yielded new team forms such as distinctions based on culture-cross-cultural, mixed-culture, and transnational teams (Earley \& Erez, 1997)—and collocation in time and space_virtual teams (Bell \& Kozlowski, in press). For example, the challenge of cross- and mixed-culture teams is to break through the barriers of different fundamental values, cultural assumptions, and stereotypes to successfully coordinate and jointly perform effectively. One of the biggest conceptual challenges in this area of work is dealing with the multiple levels-individual, group, organization, and culture - that are relevant to understanding such teams. Chao (2000), for example, presents a multilevel model of intercultural relationships that specifies how individual- and group-level interactions are affected by higher-level relationships. Essentially, interactions among individuals or groups of different cultures are affected by their cultural identities, and the relative standing of the cultures on factors important to the interaction. Variation in how groups deal with this higher-level linkage affects the quality of interaction and the potential for group effectiveness. Thus, Chao's model provides a basis to guide research on intercultural team interactions.

Bell and Kozlowski (in press) distinguish virtual teams from conventional face-to-face teams based on two features: (1) spatial distance-virtual team members are dispersed in space, and (2) technological mediation of information, data, and personal communication-virtual team members interact via advanced communications media. These two features enable diverse expertise-located worldwide - to be combined into a team that transcends the usual boundaries of space and time. As organizations and work continue to evolve, new types of work teams will be created and classified.

The Role of Typology in Understanding Teams. Although there is value in characterizing distinctions across different types of teams, description and classification are merely the first steps in comprehending the implications of such differences for effective team functioning. In our view, it is more useful to focus on the dimensions that underlie apparent differences in team classifications or typologies. Surfacing such dimensions is key to identifying the varying factors or contingencies that determine the effectiveness of different types of teams. Identifying these factors will better enable researchers and 
practitioners to specify design and operational factors that promote team effectiveness for different teams.

Some scholars have made steps in this direction. Sundstrom et al. (1990), for example, identified three dimensions underlying their typology: (1) work team differentiation-the degree to which membership is inclusive, variable, or exclusive and the span of the team's lifecycle; (2) external integration - the degree to which the team's task is entrained by, that is requires synchronization with, organizational pacers external to the team; and (3) work cycles - the general length of the team's task and the degree to which performance episodes are multiple, variable, repeatable, and novel.

Kozlowski et al. (1999) focused directly on dimensions rather than classification, proposing that five features-(1) task, (2) goals, (3) roles, (4) process emphasis, and (5) performance demandsdistinguish teams ranging along a simple to complex continuum. Complex teams are characterized by (1) tasks that are externally driven, dynamic, and structured by explicit workflows; (2) common goals that necessitate specific individual contributions that may shift over a work cycle; (3) roles that are specified and differentiated such that they required specialized knowledge and skill; (4) a process emphasis that focuses on task-based roles, task interaction, and performance coordination; and (5) performance demands that require coordinated individual performance in real-time, the capability to adapt to shifting goals and contingencies, and a capacity to continually improve over time. In contrast, simple teams are characterized by (1) tasks that are internally oriented, static, and unstructured in that they lack explicit workflows; (2) common goals that make no specific demands for individual contributions and which are fixed for the team's lifecycle; (3) roles that are unspecified and undifferentiated, such that all team members possess essentially equivalent knowledge and skill; (4) a process emphasis that focuses on social roles, social interaction, normative behavior, and conflict; and (5) by minimal performance demands that allow pooled or additive contributions to the group product. Similarly, Bell and Kozlowski (in press) characterized a continuum of team complexity ranging from simple to complex based on the dimensions of: (1) task environment, (2) external coupling, (3) internal coupling, and (4) workflow interdependence. The complex end of the continuum, relative to the simple end, is defined by tasks that are dynamic as opposed to static, external coupling that is tight rather than loose, and internal coupling that is synchronous and strong in contrast to asynchronous and weak. Workflow interdependence ranges from complex to simple as: intensive, reciprocal, sequential, and pooled (see Van de Ven et al., 1976). Looking across the dimensions described previously, we believe the following features capture most of the unique characteristics that distinguish different team forms: (1) the external environment or organizational context in terms of its (a) dynamics and (b) degree of required coupling; (2) team boundary 
permeability and spanning, (3) member (a) diversity and (b) collocation/spatial distribution; (4) internal coupling requirements; (5) workflow interdependence with its implications for (a) goal, (b) role, (c) process, and (d) performance demands; and (6) temporal characteristics that determine the nature of (a) performance episodes and cycles and (b) the team lifecycle. We offer these features as a point of departure for a concerted effort to develop a definitive set of dimensions that characterize key contingencies essential for the effectiveness of different types of teams.

We believe that continuing efforts to better characterize dimensions that distinguish different types of teams can help pay big theoretical dividends. More to the point, we believe that focusing on typology and classification is misguided if viewed as an end in itself; there is the danger of reifying classifications and failing to see underlying factors that account for apparent differences. Rather, by surfacing dimensions that distinguish teams, we will be better equipped to identify the critical contingencies relevant to effectiveness for different types of teams. Understanding what factors constrain and influence effectiveness for different types of teams will enable theoretical progress and better targeted interventions. This issue currently represents a major gap in theory and research, and substantially limits our ability to develop meaningful applications and interventions designed to enhance team effectiveness.

\section{TEAM COMPOSITION}

Events within teams often reflect the number and type of people who are its members. As a result, considerable research has focused on team composition, or the nature and attributes of team members (for a review, see Jackson \& Joshi, in press). Team composition is of research and practical interest because the combination of member attributes can have a powerful influence on team processes and outcomes. A better understanding of such effects will help practitioners to select and construct more effective teams.

Moreland and Levine (1992) categorized team composition research along three dimensions. First, different characteristics of a team and its members can be studied, including size, demographics, abilities and skills, and personalities. Second, the distribution of a given characteristic within a group can be assessed. Measures of central tendency and variability are typically used, but special configurations are sometimes measured as well. Third, different analytical perspectives can be taken toward the composition of a team. Team composition can be viewed as a consequence of various social or psychological processes (e.g., socialization), as a context that moderates or shapes other behavioral or social phenomena, or as a cause that influences team structure, dynamics, or performance.

We review and discuss team composition issues along each of these three dimensions. First, we provide a brief review of research that has focused on different characteristics of teams and their 
members. Second, we discuss issues relating to levels of conceptualization and analysis in research on team composition. Finally, we discuss some practical implications that can emerge from a better understanding of team composition and its effects on team structure, dynamics, and performance. $\underline{\text { Team Size }}$

Researchers have offered recommendations concerning the best size for various types of teams. Katzenbach and Smith (1993) suggested that work teams should contain a dozen or so members, whereas Scharf (1989) suggested that seven was the best size. A variety of other such recommendations are easily found in the literature. Such recommendations are difficult to evaluate, because they are often based on personal experiences rather than empirical evidence. However, it also difficult to determine what constitutes appropriate team size from empirical research. Some research suggests that size has a curvilinear relationship with effectiveness such that too few or too many members reduces performance (Nieva, Fleishman, \& Reick, 1985), whereas other studies have found team size to be unrelated to performance (Hackman \& Vidmar, 1970; Martz, Vogel, \& Nunamaker, 1992) or increasing team size actually improves performance without limit (Campion, Medsker, \& Higgs, 1993).

These differing recommendations and results are likely due to the fact that appropriate team size is contingent on the task and the environment in which the team operates. For example, larger teams may have access to more resources, such as time, energy, money, and expertise, that may not only facilitate team performance on more difficult tasks but also can provide more "slack" if environmental conditions worsen (Hill, 1982). However, larger teams can also experience coordination problems that interfere with performance (e.g., Lantané, Williams, \& Harkins, 1979) and motivation losses caused by a dispersion of responsibility (Sheppard, 1993). Overall, the question of the "optimal" group size is a complex one and future research is needed to determine the impact of team size given specific team contingencies, such as the nature of the team task and its consequent internal and external coupling demands.

\section{$\underline{\text { Demographic Diversity }}$}

The extent to which team processes and outcomes are influenced by the homogeneity or heterogeneity of team member demographic characteristics has also been the focus of considerable attention, although it is difficult to determine whether team diversity is desirable. Studies have reported that diversity has positive (Bantel, 1994; Gladstein, 1984), negative (Haleblian \& Finkelstein, 1993; Jackson et al., 1991; Pelled, Eisenhardt, \& Xin, 1999; Wiersema \& Bird, 1993), or even no effects on team effectiveness (Campion et al., 1993). These mixed findings have led reviewers to draw different conclusions regarding the effects of diversity: Bettenhausen (1991) concluded that groups composed of 
similar members perform better than those composed of dissimilar members, whereas Jackson, May, and Whitney (1995) concluded that diversity tends to have a positive relationship with team effectiveness.

Argote and McGrath (1993) suggested that the effect of diversity on team outcomes is likely to depend on four factors. First, the effects of diversity probably depend on the nature of the team's task. Jackson et al. (1995), for example, concluded that the value of member heterogeneity for team performance is clearest in the domains of creative and intellective tasks. Second, the effects of diversity may depend on the particular outcomes studied. Research seems to suggest that diversity may have a positive effect on performance, but a more negative effect on behavioral outcomes, such as team member turnover. Third, research has shown that the impact of diversity may vary across time. Watson, Kumar, and Michaelsen (1993), for example, found that homogeneous groups displayed better initial performance than heterogeneous groups, but these effects dissipated across time and heterogeneous groups later performed better than more homogenous groups. Finally, the impact of diversity may depend on the attributes on which homogeneity-heterogeneity is assessed. Some research suggests that diversity in demographic characteristics may have negative consequences, but diversity in terms of skills and expertise may have positive effects. Future research needs to examine these factors and how they may constrain or moderate the impact of diversity on team processes and outcomes.

\section{Dispositions and Abilities}

In addition to demographic diversity, researchers have also considered team composition effects of constructs like personality and cognitive ability on team effectiveness. Unlike demographic diversity, which is usually directly conceptualized and assessed as a team-level property (homogeneityheterogeneity), personality and ability are fundamentally individual-level psychological characteristics. Such constructs necessitate models of emergence to guide conceptualization, measurement, and representation at the team level. Many potential representations are possible including averages, highest or lowest, variance, and even complex configurations. In the absence of an explicit theoretical model of emergence to guide composition, "team personality" or "team ability" (or other such constructs) are of questionable construct validity and research may yield spurious findings (Kozlowski \& Klein, 2000).

Personality. The last decade has witnessed renewed interest in personality that has been extended to teams as researchers have examined the impact of team personality composition on team effectiveness. In general, this research has found a link between aggregate team member personality and team performance (Jackson, 1992a; Moreland \& Levine, 1992). Consistent with individual-level research, team-level conscientiousness appears to be a fairly potent positive predictor of team effectiveness 
(Barrick, Stewart, Neubert, \& Mount, 1998; Neuman, Wagner, \& Christiansen, 1999; Neuman \& Wright, 1999). Although conscientiousness has been most frequently studied, some research suggests that other Big Five personality factors, such as extraversion (Barry \& Stewart, 1997) and agreeableness (Neuman \& Wright, 1999), may also play a role in determining work team effectiveness.

Although team personality composition appears to be a relatively robust predictor of team effectiveness, research suggests that different compositions may be more or less effective depending on the task and the amount of member interaction required for effective team performance. Research has found that team-level conscientiousness is more strongly related to effectiveness for performance and planning tasks than it is for creativity and decision-making tasks (Barry \& Stewart, 1997; Neuman \& Wright, 1999). In contrast, team-level extraversion seems to have a greater impact on team effectiveness for decision-making tasks than for performance or planning tasks, possibly because the former involve a greater degree of persuasion and personal influence (Barry \& Stewart, 1997; Neuman \& Wright, 1999). Similarly, LePine, Collquit, and Erez (2000) found that team conscientiousness and openness did not predict team decision effectiveness. However, when decision rules were changed to require adaptability, conscientiousness became negative and openness positive predictors of decision effectiveness. Although the mechanisms by which team personality composition influences team performance require further investigation, it is clear that personality composition has important implications for team effectiveness.

Cognitive Ability. Among the factors studied in relation to work team effectiveness, one consistent predictor is team members' collective cognitive ability. Team members' average cognitive ability is related to team performance among military tank crews (Tziner \& Eden, 1985), assembly and maintenance teams (Barrick et al., 1998), and service teams (Neuman \& Wright, 1999). In addition, LePine, Hollenbeck, Ilgen, and Hedlund (1997) found that the performance of hierarchical decisionmaking teams was enhanced when both the leader and staff were high in cognitive ability.

A meta-analysis by Devine and Phillips (2000) found a positive relationship between average team cognitive ability and team performance of .19 , which increased to .30 when a large outlier study was omitted. Moderator analyses suggested that the relationship between team-level cognitive ability and performance is fairly consistent across information-processing and behavioral tasks. However, team-level cognitive ability exhibited a considerably stronger relationship with team performance for unfamiliar tasks $(r=.36)$ vs. familiar tasks $(r=.12)$, and the strength of the ability-performance relationship differed somewhat depending on whether the lowest member score was used $(r=.25)$ or the team average was utilized $(\mathrm{r}=.30)$. Although research in this area is promising, continued work is needed to identify those 
conditions under which team-level cognitive ability has more or less of an impact on team performance. Theoretical and Empirical Issues

Levels of conceptualization, measurement, and analysis have tended to be either ignored or treated simply in much of the research on team composition. The dominant use of averaging or additive models to guide the aggregation of individual characteristics to the team level suggests the use of simple team tasks or a very limited conceptualization of the compositional construct at the higher level (Kozlowski \& Klein, 2000). Such issues are critical for developing a sound understanding how team member attributes combine to form higher-level constructs and must be carefully articulated. Welldefined models of emergence need to guide the representation of individual-level characteristics at the team level. Kozlowski and Klein (2000) provide a differentiated typology of six different emergent processes, based on contextual constraints and interaction processes, for how lower-level phenomena manifest at higher levels. Such models can assist researchers in determining the most appropriate method for representing lower-level phenomena at higher levels. For example, when emergence is more continuous and linear, averaged or summed values are an appropriate method of representing lower-level phenomena at the team level. However, when emergence is more discontinuous and nonlinear, it is more appropriate to use dispersion or configural models to capture the emergent characteristic of the team. For example, conceptualizing team composition as a pattern of different but compatible personalities represents the use of a configural model (e.g., Stewart \& Barrick, in press).

There has also been a relative lack of attention to the latent constructs that underlie variables of interest within research on team demographic composition. As a result, it is often difficult to determine precisely how or why variables such as team member age, tenure, or demographics influence team processes and outcomes. Recent research on team personality and cognitive ability composition has placed greater attention on understanding these underlying constructs; however, additional research is needed to identify the mechanisms by which team composition has its effects.

\section{Applied Issues}

An understanding of team composition can serve as a valuable tool for selecting and constructing effective teams. Procedures could be designed to produce the optimal blend of employee characteristics (Driskell, Hogan, \& Salas, 1987; Heslin, 1964; Jackson, 1992b) including hiring new workers or firing old ones, training current workers, or engaging the services of adjunct workers, such as temporary employees or consultants (Klimoski \& Jones, 1995; Moreland et al., 1996; Stevens \& Campion, 1994).

Although past work provides some valuable information about how to manage team composition, 
researchers have often adopted a "more is better" approach (i.e., the additive model assumption) suggesting that the person with the highest score on a particular attribute (e.g., cognitive ability) or the most skilled individual should be selected for the team. However, recent research suggests that it may be more important to create an appropriate configuration of team member characteristics. For example, research by Stewart and Barrick (in press) suggests that if a team consists of a lot of extraverts, it may be better to hire a less extraverted person or even an introvert. Conversely, if a team has no extraverts, it may be important to hire highly extraverted applicants. To create an appropriate blend of team member characteristics, one will need to know what personality traits currently compose the team and the target team personality configuration before selecting a particular individual. It may also be important to consider the team's task, because it may be important to have a homogenous group of team members for some types of tasks and a heterogeneous team composition for others (Neuman \& Wright, 1999).

Human resource systems such as selection, training, and performance appraisal, must be conceptualized and managed at the team level (Schneider, Smith, \& Sipe, 2000) to appropriately address composition issues. Focusing on the individual level alone will not provide the information needed to make effective decisions regarding team composition. Including the team level provides information concerning not only the team's current composition but also the team's tasks and processes which assist in the development of an appropriate combination of team member characteristics for the task at hand.

\section{TEAM FORMATION, SOCIALIZATION, AND DEVELOPMENT}

\section{Formation}

Teams may be formed anew, where all members are new to each other and the team. Or, teams with a developmental history may have influxes and outflows of members that affect its composition and character. In either instance, development and newcomer socialization are relevant issues. Socialization has generally been seen as a mechanism for bringing new members into existing teams or groups. With few exceptions, much of this theory and research has focused on the socialization of individuals into the organization and, while theoretically relevant, has paid relatively little attention to the work group or team as central to the socialization process. That is, the vast majority of work on socialization in work settings focuses on organizational influences, but is far less sensitive to the proximal social and work context within which socialization actually takes place. While socialization is a critical aspect of team maintenance and continuance, we know relatively little about it in the team context.

Development tends to assume the formation of a brand new team with no prior history. Much of the classic theory in this area also assumes no broader organizational context, work roles, or prescribed 
interactions. Consider, for example, Tuckman's (1965) classic model of group development, with its sequential stages of forming, storming, norming, and performing. Clinical and therapy groups, which provided the foundation for this model, have no prior history, no broader context, and are almost completely unstructured save for a common goal: to "get well." Thus, the dominant focus in Tuckman's model is on the group's struggle to create structure to regulate their interpersonal interactions and to finally make progress toward the goal. Although this model — and the many, many others based on itprovides a useful contribution to our understanding of group development for simple teams, it provides little theoretical insight on skill development for work groups. As discussed in the prior section, work teams are subject to variety of structural features that drive interactions and exchanges among members. Interpersonal issues are relevant, but they do not dominate the developmental process. Yet, with few exceptions (Gersick, 1988; Kozlowski et al., 1999; McGrath, 1990; Morgan, Salas, \& Glickman, 1993), there are relatively few theories that are specifically targeted on work team development.

\section{$\underline{\text { Socialization }}$}

Existing teams are governed by a relatively stable set of norms, role expectations, and shared systems of knowledge and meaning (e.g., group climate, mental models). These informal structures emerge through social and work-based interactions among members across a group's developmental history. Newcomers present a potential challenge to this stable structure and are thus subject to efforts by group members to assimilate the person to it. At the same time, newcomers are confronted by a novel and ambiguous social and work context. While they want very much to "fit in" and "learn the ropes" and are generally prepared to accept guidance from the group, they may also seek to have the group accommodate to their needs, values, and capabilities. Thus, work group socialization is a process of mutual influence in which newcomers attempt to reduce uncertainty by learning about the work and group context; guided by group members who facilitate assimilation to existing norms, expectations, and meaning systems; while at the same time newcomers attempt to exert influence on the group to accommodate to their unique attributes and needs (Anderson \& Thomas, 1996; Moreland \& Levine, 1982).

Interestingly, even though researchers clearly recognize the centrality of the work group in the socialization process, the dominant perspective in the literature is characterized by a focus on organizational socialization-not on a primary process of work group socialization that occurs within a broader and more distal organizational context (Chao, Kozlowski, Major, \& Gardner, 1994). Virtually all efforts to identify the relevant content of newcomer socialization make provision for learning about the work group and its social structure (e.g., Chao, O’Leary-Kelly, Wolf, Klein, \& Gardner, 1994), but it is 
merely one part of a broader process. Moreover, early theory and research on organizational socialization can be characterized as accentuating the powerful influence that the organizational context exerted on newcomers in an effort to assimilate them. This was later followed by a shift in perspective that emphasized the proactive role that newcomers play in shaping their own socialization process. Missing is the sense of mutual influence as the group seeks to assimilate the newcomer, and the newcomer endeavors to adapt while seeking accommodation by the group. This is a major shortcoming of the socialization literature, and means that our knowledge of the process team socialization is limited. There are, however, some notable exceptions.

Group and Team Socialization. Moreland and Levine (1982) detail a model of group socialization that focuses on membership processes, primarily applicable to autonomous voluntary groups who control their own membership and are not nested in a broader organizational context. Its major focus is on mutual decisions on the part of a newcomer and the group regarding joining, assimilation and accommodation, and continuance or withdrawal of membership. The model spans five phases: investigation, socialization, maintenance, resocialization, and rememberance. Difficulties in assimilation or accommodation may prompt the group to resocialize a newcomer. Resocialization failure leads to lower commitment and exit. Aspects of the model are potentially relevant to team socialization-in particular its explicit attention to the group as the primary locus of socialization and mutual expectations as drivers of the process. Remarkably, although the model has been elaborated in several papers, it has generated relatively little research attention and the little research that has been conducted has been limited to ad hoc laboratory groups. Thus, the utility of the model to work team socialization remains to be examined.

Based on a focused review of the organizational socialization literature, Anderson and Thomas (1996) present a model that is explicitly focused on work group socialization and the mutual influence of the newcomer and the group on outcomes of the process. Thus, it is an effort to address the neglected issues noted above. The model spans the socialization phases of anticipation, encounter, and adjustment, identifying potential characteristics of the newcomer and the group that may contribute to socialization as a process of mutual influence and adjustment. Although the model is too recent to have prompted research, the authors provide propositions that may serve as a point of departure for such efforts.

Direct Findings for Work Group Socialization. Although most socialization research has neglected explicit attention to the role of the work group, there are some exceptions; additionally, useful knowledge regarding team socialization can be gleaned from existing research. For example, as one aspect of their study, Chao et al. (1994) focused on how the quality of newcomer role development 
relations with their leader and team influenced role outcomes of ambiguity and conflict, with the role outcomes in turn expected to influence socialization effectiveness. Results indicated that newcomer role development quality predicted role outcomes. Moreover, role outcomes were better predictors of socialization effectiveness than organizational tactics, especially over time. Chao et al. concluded that these findings supported the primacy of the work group, not the organization, as the locus of socialization.

Similarly, Major, Kozlowski, Chao, and Gardner (1995) examined the potential effects of leader and team relations on ameliorating the negative effects of unmet newcomer expectations on socialization outcomes. "Reality shock" is one of the major challenges for newcomers as they confront the unpleasant fact that their work expectations are largely unmet. An inability to resolve reality shock yields low commitment and satisfaction, and generally leads to withdrawal. Major et al. reasoned that positive relationships with work group members would moderate the effects of reality shock, weakening its relationship with negative outcomes. They reported support for their proposition, and concluded that high quality interactions with work group members provided an important support for effective socialization.

Indirect Findings for Work Group Socialization. Results from research on socialization practices indicates that newcomers view supervisors and work group members as available and helpful socialization agents who are far more helpful than formal socialization practices (Louis, Posner, \& Powell, 1983). Research on newcomer information acquisition also indicates the importance of work group members in the process of learning, sensemaking, and adjustment. Ostroff and Kozlowski (1992) hypothesized that newcomers have to resolve issues of their fit in the work group before they can turn attention to task and role issues. In support, they reported that newcomers focused on acquiring group knowledge early on, later shifting to task and role issues. Organizational factors were of lowest priority. They also found that supervisors and social learning in the group context were the most effective newcomer strategies for learning about the role and group. Perhaps most important, they reported that increasing newcomer reliance on the supervisor over time as a source of information was related to increases in newcomer satisfaction, commitment, and adjustment over time.

Role of the Group in Socialization. The research reviewed above clearly indicates that group leaders and members are key players in newcomer socialization. Unfortunately, however, this research provides little insight about group characteristics and their precise role in the socialization process. Moreland and Levine (1989) provide several suggestions in this regard. For example, they suggest that groups with a longer developmental history present a more difficult socialization challenge to the newcomer, because such groups will demand more assimilation and will resist accommodation efforts. 
There is some support for this notion. Katz (1982) reported that younger R \& D groups communicated more with outsiders and were more open to new ideas; older groups were more insular. Similarly, groups that are typified by stable membership present a more difficult socialization environment relative to groups with frequent personnel inflows and outflows. And, groups that are more successful are more likely to be insular, whereas groups experiencing performance problems may be more open to suggestions from newcomers with requisite knowledge and abilities. Groups can also apply deliberate socialization tactics. By controlling recruitment and selection they can influence the quality of fit, thereby aiding assimilation. By "encapsulating" the newcomer-maximizing their time and energy commitment to the group-they tie the newcomer to the group, minimizing alternative commitments and enhancing socialization. There is, however, little solid support for the effectiveness of these tactics in realistic team situations. More theory and research are clearly needed on work team socialization.

\section{$\underline{\text { Development }}$}

Classic Stage Models. Several models describe the developmental stages groups pass through over their life span. The descriptive characteristics of these models are remarkably parallel to Tuckman's (1965) widely cited model of group development (Kozlowski et al., 1999). Tuckman reviewed the group literature, defined by therapy, T-group, natural, and laboratory group studies, and proposed that groups go through the developmental stages of forming, storming, norming, and performing.

As team members first come together during the formation stage, they cautiously begin to explore the group and attempt to establish some social structure. They attempt to define the group task and to establish how they will accomplish it. As team members realize that defining the task is more difficult than expected, they move to the storming stage. Members argue about what actions the group should take. Different factions may form as conflict progresses. As the group finally reconciles competing loyalties and responsibilities, it begins to firmly establish ground rules, roles, and status. During this norming stage, members reduce emotional conflict and become more cooperative, developing a sense of cohesion and common goals. As these normative expectations take hold, the group moves to the performing stage. Members are able to prevent group problems, or to work through them when they arise. They become closely attached to the team and satisfied with its progress as they more toward their common goal.

Implications for Work Team Development. Although classic stage models of group development provide rich descriptions of social interaction processes, they have tended to focus on the simpler types of teams - those with tasks that have undefined workflows and internally driven processes. Thus, they focus primary attention on the interpersonal ambiguity and conflict that new group members endure as they 
attempt to create a social hierarchy with common norms to guide interactions among members.

This focus has several implications. First, the models have not been sensitive to the organizational context. When new teams form in organizations, members typically bring socialization and cultural knowledge that reduces much—-though not all—of the social uncertainty present at group formation. Second, the models have a limited conceptualization of the task, its contingencies, dynamics, and the temporal constraints these factors set on team activities. The task is often viewed as a single incident of project planning, problem solving, or decision-making that is determined by internal group dynamics; external contingencies are not acknowledged. There is no consideration of externally driven task dynamics, including variations in task complexity, difficulty, or tempo, and little recognition of multiple task episodes that cycle demands on the team. Third, the focus on unstructured task situations means that the models do not consider the development of task-relevant patterns of interaction and exchange among members that is dictated by workflow structure. Instead, group interaction is driven by interpersonal attractions and conflicts. Thus, the models tend to focus on self-insight and interpersonal processes, rather than specifying the task and team-relevant knowledge and learning that accrue during development. Fourth, the models are collectively oriented, with the group or team conceptualized as a holistic entity. This is a relevant perspective when member contributions to team outcomes represent simple aggregations. However, when composition to the higher level is represented by more complex patterns, there is a need to better disentangle the individual, dyadic, and team-level contributions. Finally, the models provide only a general description of the particular issues that arise during development, the means by which they are addressed, and the results of the process. Thus, like the socialization literature, much of the literature on team development provides relatively little insight regarding the development of work teams. There are, however, some notable exceptions.

One of the points noted above and a central theme in this chapter is the need to consider time, its dynamics, and effects. Work teams are linked to an external context that sets the pace, tempo, and cycles of team activities (Kelly, Futoran, \& McGrath, 1990), which may change over time necessitating adaptation. This has important implications for work team development, which is not necessarily a uniform series of fixed stages. Gersick $(1988,1989)$, for example, observed the developmental processes of sixteen project teams ( 8 field and 8 lab) with lifecycles ranging from a week to six months and proposed a two-stage punctuated equilibrium model (PEM) of group development. Gersick's key conclusion is that group development is not dictated by a linear progression of stages. Rather, it is linked to an external deadline that paces progress. Early group interactions establish stable norms that pattern 
group activity though an initial period of inertia. At the halfway point, a significant transformation occurs - the punctuated equilibrium - as groups reorganize to focus on task completion. This model represents an important contribution to our understanding of group development because it acknowledges that the process is influenced by external temporal contingencies in addition to internal factors. It should also be noted that the PEM may be limited to project or problem-solving teams with a single fixed objective and limited lifespan, although this does capture a substantial segment of teams in organizations.

Although the PEM is often regarded as a direct challenge to stage models of development (e.g., Guzzo \& Shea, 1992), some scholars view the two perspectives as distinctive, yet complementary. Chang, Bordia, and Duck (in press) contrasted Wheelan's (1994) integrative model of group development—a classic stage model - with Gersick's PEM. Examining 25 student project groups, they concluded that the models are complementary depending on (1) what content is addressed and (2) what unit of analysis is used in regard to time. Content that focused on group processes and structure and more micro timing tended to support linear development, whereas content that focused on the groups' approach to their task and more macro timing tended to support the PEM. These findings suggest that neither perspective alone is an adequate account of team development - we need broader, more integrative models.

Similarly, Morgan et al. (1993) formulated a model of work team development that integrated the Tuckman and Gersick models. The model was designed to apply to work teams operating in complex environments where coordination is a central aspect of effective performance. Assumptions of the model are that: (1) team development processes shift over time, (2) shifting processes form reciprocal processoutcome linkages such that intermediate outcomes serve as inputs for subsequent processes, and (3) team members acquire contextually grounded skills that lead to improvements in team effectiveness over time. This integration of Gersick and Tuckman yields a model with nine stages of development: preforming, forming, storming, norming, performing-I, reforming (punctuated equilibrium transition), performing-II, conforming, and de-forming. Another key feature of the model is the distinction made between taskwork (task relevant knowledge and skill development) and teamwork (knowledge and skills that enhance the quality of team member interactions, i.e., coordination, cooperation, communication) that must be integrated in parallel as a central aspect of the developmental process. Research by Glickman et al. (1987) provides general support for the primary assumptions of the model and, in particular, the distinction between taskwork and teamwork skills and their necessary integration for team effectiveness.

More recently, Kozlowski and colleagues (1999) have proposed a normative model of team compilation that integrates team development with a performance perspective. That is, team performance 
and adaptability at any given point in time are viewed as dynamic consequences of a continuous developmental process. There are three key conceptual features of the theory. First, temporal dynamics are viewed in terms of both linear and cyclical time, representing the effects of developmental processes and task episodes, respectively. Team capabilities improve developmentally prompting transition to more advanced phases of skill acquisition. Within a phase, variations in task episodes or cycles provide opportunities for learning and skill acquisition (see also Kozlowski et al., 1996a; Kozlowski, Gully, Salas, \& Cannon-Bowers, 1996b). Second, developmental transitions prompt attention to different content that is the focus of new learning, different processes by which knowledge and skills are acquired, and different outcomes that capture current capabilities. Third, team compilation is viewed as an emergent multilevel phenomenon. Knowledge, skills, and performance outcomes compile successively upwards across focal levels from an individual self-focus to dyadic exchanges to an adaptive team network.

The model is formulated around four phase transitions, each with a distinct focal level and content, process, and outcome specifications. In phase 1, individuals are focused on resolving their fit in social space through a socialization process. This yields outcomes of interpersonal knowledge and team orientation, providing a foundation for shared norms, goals, and climate perceptions. In phase 2, individuals focus on acquiring task knowledge via skill acquisition processes with outcomes of task mastery and self-regulation skills. In phase 3, the level shifts to dyads that must negotiate role relationships, identifying key role sets and routines to guide task driven interactions. In phase 4 , the level shifts to the team as it creates a flexible network of role interdependencies that will enable continuous improvement and adaptability to novel and challenging demands. Although there are no direct tests of the model, it is synthesized from a substantial and diverse literature. DeShon, Kozlowski, Schmidt, Wiechmann, and Milner (2001) provide preliminary support for the basic proposition that developmental shifts in focal level from individual to team contribute to team performance adaptability.

\section{$\underline{\text { Research Implications and Application Issues }}$}

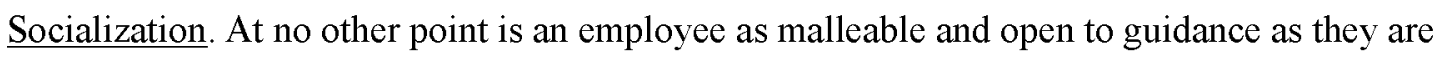
during their initial encounter with the organization and their work group. This provides an obvious opportunity to have a long-term influence on the shaping of new employees that has not gone unnoticed by organizations. Indeed, the vast majority of organizations make some formal effort to socialize newcomers to inculcate norms, goals, and values via training, induction, and orientation programs (Anderson, Cunningham-Snell, \& Haigh, 1996). Yet, the available evidence suggests that these formal efforts have only moderate and transitory effects, which are swamped by the more intense and proximal 
socialization processes that occur within work groups (Anderson \& Thomas, 1996; Chao et al., 1994a).

We know that team leaders and work group members play a critical role in newcomer socialization. Given this clear impact, some have suggested that it may be a useful strategy to train team leaders and group members to be more effective socialization agents (Ostroff \& Kozlowski, 1992). To our knowledge, no such efforts have been pursued and evaluated. Thus, for the most part, the effectiveness of this more local process is accidental, dependent on the mutual proaction of newcomers and their work groups. This issue has clear application potential that has not been sufficiently explored and leveraged.

While the importance of the work group as a key agent in socialization is recognized implicitly by the literature, it has largely neglected the importance of newcomer socialization to the group. It is in the work group's vested interest to socialize newcomers. It helps to maintain existing norms, expectations and shared systems of meaning; it enhances social and work interactions; and it is essential to long-term group functioning. Thus, while we know how and what newcomers try to learn from work group members, we know far less about the precise role of the group in the process. What group characteristics influence the process and how? What tactics do groups use to prompt assimilation and resist accommodation? What are the effects of different group characteristics and tactics - in interaction with newcomer characteristics and tactics—on the socialization process, group functioning, and group effectiveness? These are critical research questions that for the most part remain to be explored in future research. We believe that progress on elucidating work group socialization will necessitate another shift in research perspective in the socialization literature, one that takes a contextual approach-focusing on the newcomer in the group context, one that is sensitive to multiple levels-newcomers, dyadic relationships with group members, and the group as a whole, and one that models the emergent effects of newcomer assimilation and group accommodation processes on group responses across levels and over time.

Development. Like socialization, the formative period of team development offers an unprecedented opportunity to shape the nature and functioning of new teams. Unfortunately, unlike socialization where there is a growing empirical foundation, there is relatively little research addressing work team development. What we know about the process is largely based on extrapolations from case studies examining other types of teams (Tuckman, 1965) or on the relatively few observational studies of work team development-studies that tend to be based on very few teams. For the most part, the work team development process remains largely unexplored.

In some ways, the area of team development may be paralleling and lagging its socialization counterpart. Two decades ago, the socialization area was typified by classic descriptive theories that were 
primarily focused on voluntary groups. Empirical research was spotty, and not of the highest quality. Then, there was a period of theory development specifically targeted on organizational socialization that subsequently stimulated many empirical advances. Today, socialization is a vibrant area of theory development and research. The team development area is like socialization two decades ago. We are beginning to see the creation of new theories specifically focused on work team development that move beyond the classic descriptive models. Hopefully, these and other new theories will stimulate rigorous empirical research on work team development. For example, further research to validate and extend Gersick's model (1988) is needed. If the punctuated equilibrium is a universal phenomenon in project groups and other types of teams, surely interventions to accelerate the initial unproductive phase can be created to help improve the efficiency and effectiveness of the team development process. Similarly, research to validate the content, processes, and outcomes specified for the phases of team development by Kozlowski et al. (1999) would provide a foundation for creating interventions that promote team development at all stages of a team lifecycle. For now, however, the process of team development, and its resulting quality, is largely taken as a matter of faith - leaders and teams are expected to muddle through and figure it out. From an applied perspective, one can't help but marvel at the magnitude of the lost opportunity to influence long-term team effectiveness.

\section{TEAM EFFECTIVENESS, PROCESSES, AND ENHANCEMENTS}

From an organizational psychology perspective, team effectiveness is the core focus of theory and research on teams. All topics addressed in this chapter bear on team effectiveness in one way or another. There are literally thousands of articles addressing this topic, far too many for us to capture. Our intent, therefore, is to briefly characterize key aspects of models of team effectiveness, and then to focus primary attention on those topics that uniquely distinguish the organizational approach from that of its progenitors - that is, on processes relevant to work-driven team member interactions, the nature of team performance, and interventions designed to enhance team processes and team performance.

\section{$\underline{\text { Team Effectiveness }}$}

Most models of team effectiveness begin where most models of team development end. Models of team effectiveness generally assume mature teams that have completed a formative developmental process. Most models of team effectiveness are at least loosely formulated around an Input-ProcessOutcome (IPO) framework posited by McGrath (1964); inputs are the primary cause of processes that in turn mediate the effect of inputs on outcomes. Inputs represent various resources available to the team both internally (e.g., composition of KSAs, personalities, demographics; group structure, team design) 
and externally (e.g., rewards, training; organizational climate) at multiple levels (e.g., individual, group, organization). Processes represent mechanisms that inhibit or enable the ability of team members to combine their capabilities and behavior. Although the small group literature has generally focused on dysfunctional processes that yield process losses (Steiner, 1972), the focus of team effectiveness is on synergies that produce process gains (Hackman, 1987). At a global level, examples include coordination, cooperation, and communication (Tannenbaum, Beard, \& Salas, 1992). Outcomes represent criteria to assess the effectiveness of team actions. Team effectiveness is generally conceived as multifaceted, with an emphasis on both internal (i.e., member satisfaction, team viability) and external (i.e., productivity, performance) criteria (Hackman, 1987). In practice, team effectiveness is broadly defined and assessed in various ways. It therefore lacks the precision of a theoretical construct; one must look to its specification for particular types of teams to determine its grounded meaning (Goodman et al., 1987). Space precludes an examination of specific models. Good exemplars, however, include Gladstein (1984), Hackman (1987), and Tannenbaum et al. (1992).

Relative to models of team development, team effectiveness models are more static in nature. This is due in large part to the assumed causal linkage inherent in the IPO heuristic, and the way that process is represented—by a box. Theorists do acknowledge linear time (McGrath, 1964), reciprocal linkages (Hackman, 1987), and feedback loops (Tannenbaum et al., 1992) to capture different temporal dynamics. Nevertheless, effectiveness criteria are generally treated as retrospective summaries, and designs to evaluate team effectiveness models tend to be based on cross-sectional, static data (Goodman et al., 1987). Time is relatively unappreciated in most perspectives on team effectiveness (Kozlowski et al., 1999). McGrath's (1991) Time-Interaction-Performance (TIP) model is a rare exception in this regard. Although the IPO framework lends structure to many models of team effectiveness, thereby creating a substantial degree of similarity across models, there are also some important differences. One key difference worth highlighting concerns whether processes are caused by input factors (i.e., mediators) or whether they are better conceptualized as contingencies (i.e., moderators) that affect the input to output linkage. The former point of view is more representative of the small group research perspective and is a major reason why that tradition has tended to focus on process losses that stem from natural patterns of group interaction (e.g., Steiner, 1972). In contrast, the latter point of view is more representative of a normative approach that conceptualizes processes as mechanisms that enable the group to fit patterns of interaction to team task design and workflows (e.g., Hackman, 1987). This latter perspective is interventionist in orientation and, whether it explicitly conceptualizes processes as moderators or not, 
seeks to specify appropriate patterns of interaction and exchange and to intervene through training, leadership, or other techniques to improve the fit of team processes with task-driven requirements to enhance team effectiveness (e.g., Hackman, 1987; Kozlowski et al., 1996a, 1996b, 1999; Tannenbaum et al., 1992). This naturally raises the question, what process mechanisms enable team effectiveness?

\section{$\underline{\text { Team Processes }}$}

Like the effectiveness area, there is an extensive literature on team processes, the concept itself is so broadly defined as to be ill defined, and there is little convergence on a core set of processes. Much of the small group literature primarily addresses "natural" group processes that unfold in voluntary groups that have no broader embedding context (i.e., the organization) and no task-driven interdependencies, hence, the focus on interpersonal processes involved in group attraction (e.g., cohesion) and divisiveness (e.g., conflict). Although such processes are certainly of relevance to work teams, other process mechanisms are more relevant to fitting team member interactions to task workflows. To organize our review of team processes, we focus on cognitive, affective/motivational, and behavioral mechanisms.

Cognitive Constructs and Mechanisms. Three primary cognitive mechanisms are represented in the literature: team mental models, transactive memory, and team learning. Team Mental Models are team members' shared, organized understanding and mental representation of knowledge about key elements of the team's task environment (Klimoski \& Mohammed, 1994). Four content domains underlying team mental models have been proposed (Cannon-Bowers, Salas, \& Converse, 1993): (1) equipment modelknowledge of equipment and tools used by the team; (2) task model—understanding about the work that the team is to accomplish, including its goals or performance requirements and the problems facing the team; (3) member model-awareness of team member characteristics, including representations of what individual members know and believe, their skills, preferences, and habits; and (4) teamwork modelwhat is known or believed by team members with regard to what are appropriate or effective processes.

Related to team mental models, but at a much higher level of generality, are conceptualizations of Team Climate. Team climate represents group-level shared perceptions of important contextual factors that affect group functioning, and via mediating climate perceptions affect group outcomes. For example, Hofmann and Stetzner (1996) have demonstrated that team safety climate affects team safety behaviors and outcomes. Similarly, Anderson and West (1998) have developed the Team Climate Inventory as a tool to improve team innovation. Variations in the extent to which climate is shared at the team level has been shown to affect its linkage with team outcomes (González-Romá, Peiró, \& Tordera, in press).

Team Coherence (Kozlowski et al., 1996a) is another variant of the team mental model construct. 
The main difference is that coherence does not assume that team members share all knowledge identically, rather some knowledge specific to individuals is different but compatible or complementary. Team coherence is presumed to form on the basis of developmental processes that unfold over time, shared experiences, and leader facilitation. Complementary cognition and behavior, along with shared affect and climate perceptions, provide a foundation for essential teamwork capabilities. When a team is guided by a shared comprehension of its task situation and its corresponding goals, strategies, and role linkages, it is able to adapt to task variations and to maintain synchronicity without explicit directives (Kozlowski et al., 1996a). This sharing represents an integration of taskwork and teamwork capabilities.

The general thesis of the shared mental model literature and its variants is that team effectiveness will improve if members have an appropriate shared understanding of the task, team, equipment and situation (e.g., Cannon-Bowers et al., 1993; see March 2001 issue of Journal of Organizational Behavior for articles on shared cognition). Empirical work, however, has lagged behind conceptual development (Mohammed \& Dumville, 2001). Some early research used team mental models as a post hoc explanation for observed performance differences among teams, although more recent research has measured the construct more directly. For example, Mathieu, Heffner, Goodwin, Salas, and Cannon-Bowers (2000) examined the effect of shared mental convergence on team processes and performance using two-person, undergraduate teams performing a PC-based flight/combat simulation. Results indicated that teamwork and taskwork mental models related positively to team process and performance, and that team processes fully mediated the relationship between shared mental models and performance. Minionis, Zaccaro, and Perez (1995) used concept maps to examine shared knowledge among team members in a computersimulated tank exercise. Results indicated that shared mental models enhanced performance on collective tasks requiring member interdependence, but did not affect tasks that could be completed without coordinated action. Using a similar paradigm, Marks, Zaccaro, and Mathieu (2000), indicated that the quality of team mental models positively influenced communication processes and performance. Thus, although empirical support is limited, emerging findings support the general thesis that appropriate team mental models have positive effects on team processes and effectiveness.

These research findings suggest that the development of team mental models is a promising leverage point for interventions to improve team effectiveness. Several methods for fostering the development of team mental models have been proposed, including team planning (Stout, CannonBowers, Salas, \& Milanovich, 1999), computer-based instruction (Smith-Jentsch, Milanovich, Reynolds, \& Hall, 1999), and team self-correction training (Blickensderfer, Cannon-Bowers, \& Salas, 1997). For 
example, team self-correction training involves the following elements: (1) event review, (2) error identification, (3) feedback exchange, and (4) planning for the future. Team self-correction can be enhanced through training in skills such as providing feedback, situational awareness, and assertiveness. Similarly, Kozlowski and colleagues (1996a, 1996b) posit that leaders can play a central role in developing team coherence by leading the team through an iterative four-step learning cycle that makes use of: (1) goal-setting, (2) performance monitoring, (3) error diagnosis, and (4) process feedback. Providing support for these perspectives, Marks et al. (2000) enhanced team mental models with leader pre-briefs regarding effective strategies to use. Smith-Jentsch, Zeisig, Acton, and McPherson (1998) also used structured leader pre- and debriefs to enhance team mental models and performance.

Transactive Memory is a group-level shared system for encoding, storing, and retrieving information; a set of individual memory systems which combines knowledge possessed by particular members with shared awareness of who knows what (Wegner, 1986; Wegner, Giuliano, \& Hertel, 1985). It was introduced to explain how intimate relationships (i.e., dating couples) foster the development of shared memory. The development of transactive memory involves communicating and updating information each partner has about the areas of the other's knowledge. In essence, each partner cultivates the other as an external memory aid, and in so doing becomes part of a larger system. The application of the concept to work teams involves a similar logic. Each team member keeps current on who knows what, channels incoming information to the appropriate person, and has a strategy for accessing the information (Mohammed \& Dumville, 2001). In addition to knowing who is the expert in different knowledge areas, transactive memory also involves storing new information with individuals who have matching expertise and accessing relevant material from others in the system (Wegner 1986, 1995).

Transactive memory is presumed to offer teams the advantage of cognitive efficiency. Through the encoding and information allocation processes, individual memories become progressively more specialized and are fashioned into a differentiated collective memory that is useful to the group. The knowledge specialization that individuals develop within a transactive memory system reduces cognitive load, provides access to an expanded pool of expertise, and decreases redundancy of effort (Hollingshead, 1998b). On the downside, however, the complexity of transactive memory can create confusion, especially when expertise is in dispute and important information falls through the cracks (Wegner, 1986). There is also the potential problem of time lags to acquire needed information. When performance is time-critical, such lags are likely to adversely affect team effectiveness.

Like team mental models, empirical research on transactive memory lags behind theoretical 
development. Because the concept was introduced to explain the behavior of intimate couples, most research has examined dyads (e.g., Hollingshead, 1998a, 1998b). There is some work addressing transactive memory in work groups. Liang, Morleand, and Argote (1995) trained undergraduates to assemble a radio either individually or in groups. Trainees were later tested with their original group or in a newly formed group. Evidencing stronger transactive memory systems, members of groups trained together specialized in remembering different aspects of the task, coordinated behaviors more effectively, and displayed greater trust in each other's expertise. Moreover, the effects of group training on task performance were mediated by the operation of transactive memory. Moreland (2000) conducted a follow-up using a similar design and task. Transactive memory was measured more directly through the complexity of group members' beliefs about one another's radio expertise, and the agreement and accuracy of those beliefs. Lewis (2000) has begun to validate field measures and to establish the link between transactive memory and team performance in organizational settings.

Although this area is still in its infancy, some research and practical recommendations can be offered. From a research perspective, most work on transactive memory has been conducted with couples in the laboratory using contrived tasks. Thus, future research needs to focus on work teams and how transactive memory emerges and is maintained in field contexts (Mohammed \& Dumville, 2001). From a practical perspective, the nature of communication media in teams may be important for fostering and maintaining transactive memory. Hollingshead (1998b), for example, found that couples working via a computer conferencing system performed more poorly on a knowledge-pooling task than couples that worked face-to-face. Those results and a follow-up suggest that both nonverbal and paralinguistic communication play an important role in the retrieval of knowledge in transactive memory systems. Finally, research by Moreland and colleagues $(1995,2000)$ suggests that training intact teams may be useful for developing transactive memory systems.

Team Learning refers to relatively permanent changes in the knowledge of an interdependent set of individuals associated with experience, and can be distinguished conceptually from individual learning. Argote, Gruenfeld, and Naquin (1999), for example, found that skilled individual learners will not necessarily result in a team that learns collectively. Edmonson's (1999) model of team learning suggests that psychological safety-a shared belief that the team is safe for interpersonal risk taking-contributes to team learning behaviors, such as seeking feedback, sharing information, experimenting, asking for help, and talking about errors. These behaviors are then presumed to facilitate performance by allowing the team to shift directions as situations change and discover unexpected implications of team actions. 
Very little research has examined team learning. Argote, Insko, Yovetich, \& Romero (1995) examined the effects of turnover and task complexity on group learning in a laboratory. They reported a group learning curve: The performance of groups making origami birds increased significantly over six periods, with the performance increase occurring at a decreasing rate. Turnover and task complexity were detrimental to performance, and the differences between turnover and no turnover groups as well as simple and complex task groups were amplified as groups gained experience over time. Edmonson (1999) examined team learning in an organizational context, reporting that team psychological safety positively affected learning behaviors, which in turn positively affected team performance. Cannon \& Edmondson (2000) found that learning oriented beliefs promoted group performance and that effective coaching, clear direction, and a supportive work context were antecedents of group learning.

Although this work is still in its formative stage, some research and practical recommendations may be noted. From a research perspective, the empirical work is weak. First, and most critically, learning or knowledge is rarely assessed directly. Instead, team learning is assumed from changes in team performance and/or behavior. Thus, there is a clear need for research to directly measure changes in both individual and team knowledge, clearly distinguish collective knowledge from individual knowledge, separate team learning from other team cognitive constructs (i.e., team mental models, transactive memory) and from team performance. Until these issues are addressed, the standing of team learning as a meaningful and useful construct remains murky. A second and related limitation is that many of the variables examined as having an impact on team learning, such as turnover, may have impacts on team performance apart from affecting team learning. In other words, while turnover may impact the "collective" knowledge of the team, it also may influence communication patterns, induce socialization efforts, affect team mental models, and so forth which may ultimately impact team performance. Thus, it is important for researchers to demonstrate that variables, such as turnover and task complexity, have an impact directly on team learning. Finally, besides Edmonson's work, there has been little effort to specify the process by which team learning occurs. What are the conditions that facilitate team learning? How is the process different from individual learning? How does team learning emerge from individual learning? There are levels of analysis issues that need to be explicitly addressed to better understand whether the process of learning is similar or different at the individual and team levels (Kozlowski \& Klein, 2000).

Affective and Motivational Constructs and Mechanisms. There are four primary team process constructs or mechanisms that can be classified as affective, affectively related, or motivational in nature: (1) cohesion, (2) collective mood or group emotion, (3) collective efficacy, and (4) conflict and 
divisiveness. We address each of these processes in turn.

Team researchers have offered multiple definitions of Cohesion. Festinger (1950) defined cohesiveness as "the resultant of all the forces acting on the members to remain in the group" (p. 274). Goodman et al. (1987) defined cohesion as the commitment of members to the group's task. Evans and Jarvis (1980) concluded that "member attraction to the group" (p. 360) is the most common definition of cohesion. Mixed results for the effects of cohesion on performance, however, have led researchers to suggest that it may be multidimensional. Gross and Martin (1952) described cohesion in terms of two underlying dimensions, task cohesion and interpersonal cohesion. Task cohesion is defined as a group's shared commitment or attraction to the group task or goal, and is thought to increase commitment to the task and to increase individual effort by group members on the task. Interpersonal cohesion is defined as the group members' attraction to or liking of the group (Evans \& Jarvis, 1980). Interpersonal cohesion allows groups to have less inhibited communication and to effectively coordinate their efforts.

Research findings tend to support the multidimensional view. For example, a meta-analysis by Mullen and Copper (1994) distinguished three types of cohesion: (1) interpersonal cohesion, (2) task cohesion, and (3) group pride. They concluded that task cohesion is the critical element of group cohesion when the cohesion-performance relationship is examined, and that interpersonal cohesion might do little more than cause members to exert only as much effort as required to remain in the group. Zaccaro and Lowe (1988) found that only task cohesion was important for an additive task; interpersonal cohesion had no impact. On a disjunctive task, however, Zaccaro and McCoy (1988) found that the best group performance occurred when groups had both high levels of task cohesion and interpersonal cohesion.

Although it has been observed that a cohesive group may engage its energies in high performance or its restriction (Seashore, 1954), most empirical research has supported a positive relationship between cohesion and group performance across a wide variety of team types (Evans \& Dion, 1991; Greene, 1989; Hambrick, 1995; Katzenbach \& Smith, 1993; Mullen \& Copper, 1994; Smith et al., 1994). However, several important issues remain to be firmly resolved with respect to the effects of cohesion on team effectiveness. First, the relative impacts of task and interpersonal cohesion may depend on the effectiveness outcome being examined. For example, Mullen and Copper (1994) found that task cohesion had the largest impact on team performance, presumably because it increases task commitment. In contrast, Barrick et al. (1998) found that social cohesion positively impacted ratings of team viability. Second, task type may operate as a moderator of cohesion effects. Gully, Devine, and Whitney (1995) suggested that cohesive groups perform well on interdependent tasks because they can coordinate better, 
whereas coordination is unimportant for more independent tasks. Research supports this suggestion and has found that cohesion has less of an effect when the team task is additive. In fact, some researchers have suggested that cohesion can be detrimental for additive tasks because it partially focuses group effort onto social development rather than concentrating just on the task (Lott \& Lott, 1965).

Two practical recommendations can be offered for enhancing team cohesion. First, it may be important to have the right mix of individuals to enhance team cohesion. Barrick et al. (1998) found that teams high in extraversion and emotional stability had higher levels of social cohesion. Second, clear norms and goals may help teams to develop both task and interpersonal cohesion, although it is difficult to know precisely the direction of this relationship. Thus, using selection to manage group composition and team development to inculcate norms and goals may be useful ways to establish cohesive groups.

Collective Mood or Group Emotion captures the idea of group affective tone. Barsade and Gibson (1998) argue that two approaches—-top down and bottom-up—can be used to understand group emotion. The top-down approach views the group as a whole and leads researchers to examine how the feeling and behaviors of individuals arise from group dynamics. It is characterized by four streams of research that treats group emotion as: (1) powerful forces which dramatically shape individual emotional response (e.g., psychological effects of crowds); (2) social norms that prescribe emotional feelings and expression (e.g., sets of socially shared norms about how individuals should feel and how they should express those feelings in particular situations); (3) the interpersonal glue that keeps groups together (e.g., group cohesion); and (4) a window to viewing a group's maturity and development (e.g., group emotions have been used to understand the temporal development of groups). The bottom-up approach examines the ways in which individual level emotions combine at the team level to influence outcomes, and is represented by three research foci: (1) mean level affect, (2) affective homogeneity/heterogeneity, and (3) the effects of minimum-maximum team member affect on the group.

Shaw (1976) suggested that there is consistent evidence that group effectiveness, cohesiveness, morale, group motivation, and communication efficiency are positively related to the composition of such individual-level attributes as adjustment, emotional control, and emotional stability, and negatively related to such attributes as depressive tendencies, neuroticism, paranoid tendencies, and pathology. Some researchers have suggested that affective homogeneity is beneficial because research has shown that similarity between individuals creates attraction (Schneider, 1987). Similar to the effects of group composition, it has been argued that teams with members who are more similar affectively will be more comfortable with each others' interpersonal interactions, thereby generating more cooperation, trust, 
social integration, and cohesion. This in turn should positively influence group outcomes. For example, Barsade, Ward, Turner, and Sonnenfeld (1998) examined the dispositional positive affective similarity among members of senior management teams and found that affective similarity has a positive effect on group outcomes. On the other hand, some group composition research has shown that affective heterogeneity can be beneficial for some outcomes such as creativity (Jackson, 1992b). Barsade and Gibson (1998) suggest that it may be good when the affective qualities of individuals complement one another (e.g., pessimist and optimist, low energy and high energy, etc.). Finally, it may be possible to take the idea of minority influence and examine it from an affective perspective. Barsade (1998) suggests that a single person can have a strong influence on group affect. A person who has strong dispositional negative affect, or vice versa, may infect the team with his or her negativity and the team's mood may become much more negative than would be expected from its mean-level dispositional affect.

Although the ideas regarding the effects of group emotion on team effectiveness are provocative, several important issues need to be resolved. First, more empirical support is needed. Most of Barsade's ideas are drawn from research on group composition and other topics. Barsade draws parallels suggesting that similar effects may occur when the compositional variable of interest is affect. However, aside from a few empirical studies, most of these issues remain unexamined. Research is clearly needed. Second, Barsade and Gibson (1998) make clear reference to top-down and bottom-up levels of analysis issues. It is important for research to address these issues with precision to better understand the impact of grouplevel affect on individual-level variables and vice versa (Kozlowski \& Klein, 2000).

The potential practical implications of this work are tempered by the need for more basic research. For example, while there is some support for a relationship between dispositional affect and job skills (see Staw, Sutton, \& Pelled, 1994 for a review), the research is not yet specific enough to be able to determine how this would transfer across different group contexts. Such research is necessary to determine the most effective ways of influencing group outcomes through affect. Is it best to control group affect by establishing norms, or will it be more effective to select team members based on affective individual differences? Similarly, managers may need to influence the impact of maximum and minimum group members because these members - through contagion — can have a strong influence on the affect of the group. Or, there may be a need to manage affective heterogeneity or homogeneity. Selection as a means to manage group composition may be a useful tool in this regard. However, far more research will have to be conducted before there is a sufficient foundation for specific practical recommendations.

Bandura's (1997) concept of collective efficacy is defined as a group's shared belief in its own 
collective ability to organize and execute courses of action required to produce given levels of attainment. Zaccaro, Blair, Peterson, and Zazanis (1995, p. 309) defined collective efficacy as "a sense of collective competence shared among members when allocating, coordinating, and integrating their resources as a successful, concerted response to specific situational demands." Shea and Guzzo (1987, p. 335) defined a similar construct, called group potency, as "the collective belief of a group that it can be effective." Although many scholars view these two constructs as similar, Guzzo, Yost, Cambell, and Shea (1993) asserted that collective efficacy is task specific and group potency is a more general shared belief about group effectiveness across multiple tasks. It is generally presumed that a well-developed structure and interactive or coordinative task processes are necessary or at least a sufficient condition for shared efficacy beliefs to develop (Paskevich, Brawley, Dorsch, \& Widmeyer, 1999). In other words, there needs to be a common foundation to foster shared judgments of future effectiveness. Similar to individual-level efficacy, collective efficacy is hypothesized to influence what a group chooses to do, how much effort it will exert in accomplishing its goal, and its persistence in the face of difficulty or failure (Bandura, 1986).

Some of the initial research examining the effects of collective efficacy has focused on physical tasks and the performance of sports teams. For example, Hodges and Carron (1992) found that triads high in collective efficacy improved their performance on a muscular endurance task following a failure experience, whereas triads low in collective efficacy experienced a performance decrement. In the field, Feltz and Lirgg (1998) found that ice hockey teams with higher levels of collective efficacy performed better. Similar results have been reported for work teams. Virtually all the studies that have examined this issue have found a positive relationship between collective efficacy and work team effectiveness (e.g., Campion et al., 1993; Edmondson, 1999; Hyatt \& Ruddy, 1997). In addition, a recent meta-analysis by Gully, Joshi, and Incalcaterra (2001) examining 159 effect sizes from 56 empirical studies concluded that team efficacy is a strong predictor of team performance $(\rho=.40)$.

There are three important issues that need to be addressed by continuing research on collective efficacy: (1) levels of analysis concerns in measurement, (2) elucidation of the underlying process, and (3) examination of potential contextual moderators. First, Gist (1987) suggested three methods of assessing collective efficacy: (1) aggregating individual perceptions of self-efficacy, (2) averaging individuals' perceptions of collective efficacy, or (3) using consensual group responses to a single questionnaire. The third approach has been criticized because it ignores the variability that exists when beliefs are not shared (Bandura, 1997). A fourth approach, suggested by Lindsley, Brass, and Thomas (1995), has individual members estimate the group's belief that it can perform a specific task that 
contrasts with an individual's view about what he or she alone believes the group can do. Levels of analysis theorists recognize these alternatives as distinctly different conceptualizations of the higher level construct relative to its individual-level origins (e.g., Chan, 1998). Thus, research needs to examine differences in meaning and effect among these different versions of collective efficacy. Second, research is needed to examine exactly how collective efficacy influences team performance. Paskevich et al. (1999) found that certain aspects of multidimensional collective efficacy were related strongly to taskbased aspects of cohesion. Through what mechanisms does collectively efficacy develop and have impact? Is it analogous to individual self-efficacy, or are there distinctive mechanisms at the team level? Thus, research needs to elucidate the underlying process and to distinguish individual- and team-level effects. Third, it is likely that contextual factors such as the team task and culture, among others, may affect the linkage between collective efficacy and team effectiveness. Gibson (1999) found that when task uncertainty was high, work was independent, and collectivism was low, group efficacy was not related to group effectiveness. However, when task uncertainty was low, work was interdependent, and collectivism was high, the relationship between group efficacy and group effectiveness was positive.

Based on the supportive research findings, it is reasonable to assert that high collective efficacy is generally a desirable team characteristic. From a practical perspective, the relevant question is how can collective efficacy be fostered? Unfortunately, most research has examined the collective efficacyperformance relationship. There has been much less attention focused on the antecedents of collective efficacy making it difficult to provide firm recommendations on how managers and organizations can build efficacy at the team level. However, one might assume that many of the factors shown to influence individual-level self-efficacy may be relevant, at least as a point of departure. Thus, future research should consider team-level goal orientation, regulatory focus (DeShon et al., 2001), attributional processes, and success/failure experiences, especially early in a team's lifecycle.

Most of the process constructs and mechanisms discussed thus far are oriented toward forces that push team members together. Shared mental models, team learning, cohesion, collective efficacy are forces for convergence. And, clearly, the image of a team as a 'well oiled machine' characterizes our interest in those processes that yield synergy and the enhancement of team effectiveness. Yet, it is also the case that teams are not always characterized by convergence. Indeed, divergence, divisiveness, and conflict are common phenomena in teams and organizations (Brown \& Kozlowski, 2000). For example, Lau and Murnighan (1998) describe how demographic differences can split a group along "faultlines" into competing and divisive entities. Brown and Kozlowski (2000) present a Dispersion Theory that 
focuses on latent constructs (e.g., perceptions, values, beliefs). In their model, convergent and divergent processes can operate simultaneously within and across groups, affecting the nature of emergent collective constructs. Sheremata (2000) argues that groups and organizations are characterized by both centrifugal forces—which push the entity apart—and centripetal forces—which pull it back together. Conflict is a manifestation of the processes underlying faultlines, divergence, and centrifugal forces. Work teams provide an interpersonal context in which conflict is likely; It must then be managed because it is often detrimental to team performance (Jehn, 1995). Marks et al. (2001) identified two conflict management strategies: (1) preemptive conflict management involves establishing conditions to prevent, control, or guide team conflict before it occurs; whereas (2) reactive conflict management involves working through task, process, and interpersonal disagreements among team members. Most research has focused on reactive conflict management strategies, such as identification of the parameters of conflict between team members, problem solving, compromising, openness and flexibility, and willingness to accept differences of opinion. Although more limited, there has been some work on preemptive conflict management such as establishing norms for cooperative rather than competitive approaches to conflict resolution (Tjosvold, 1985), using team contracts or charters to specify a priori how team members agree to handle difficult situations (Smolek, Hoffman, \& Moran, 1999), and developing team rules and norms about the nature and timing of conflict (Marks et al., 2001).

Recent research has shed light on several important aspects of intra-team conflict and provides promise for developing better conflict management in teams. Some research suggests that conflict may be beneficial for teams; it depends on the types of conflict and task. For example, Jehn (1995) found that for groups performing routine tasks, both task conflict (disagreement about task content) and relationship conflict (interpersonal incompatibilities) were detrimental. However, for groups performing nonroutine tasks, only relationship conflict was detrimental. In fact, at times, task conflict was beneficial for groups performing nonroutine tasks. Similarly, Amason (1996) found that higher levels of cognitive conflict (task based) and lower levels of affective conflict (relationship based) led to increased effectiveness in top management teams. Furthermore, research by Simons and Peterson (2000) found that top management teams low in interpersonal trust tended to attribute conflict to relationship-based issues, whereas top management teams high in interpersonal trust tended to attribute conflict to task-based disagreements Thus, interpersonal trust may be an important variable to consider when managing conflict in teams.

Behavioral Constructs and Mechanisms. There are three primary topics that can be classified as observable process mechanisms that influence team effectiveness: (1) coordination, (2) cooperation, and 
(3) communication. We acknowledge at the outset that these three concepts are often ill defined and difficult to clearly separate. However, we argue that coordination involves a temporal component that is not an essential part of cooperation or collaboration, and that communication is frequently a means to enable coordination or cooperation, but is distinguishable from the other two.

Coordination can be defined as activities required to manage interdependencies with the team workflow. The notions of (a) integrating disparate actions together in concert with (b) temporal pacing or entrainment are central to the conceptualization of coordination (Argote \& McGrath, 1993). Its essential elements and underlying processes include (Zalesny, Salas, \& Prince, 1995): (1) goals (e.g., identifying goals through conflict and resolution), (2) activities and tasks (e.g., mapping goals to activities through leadership), (3) actors/team members (e.g., task assignment), and (4) interdependencies (e.g., resource allocation, sequencing, and synchronization). Coordination is vital to group effectiveness in situations where a successful outcome for the entire group is the end result of numerous contributions or efforts by all group members (i.e., integration) and where successful contributions by one participant are contingent on a correct and timely contribution by another participant (i.e., temporal entrainment).

Several operationalizations have been used to capture team coordination behavior. Assessments consistent with the conceptualization sketched above have focused on temporal response patterns and sequential analysis (Zalesny et al., 1995), such as using observer ratings of communication patterns (Brannick, Roach, \& Salas, 1993), measuring the amount of time one team member waits for another before engaging in a joint effort (Coovert, Campbell, Cannon-Bowers, \& Salas, 1995), and using Petri nets and artificial neural networks to model and analyze ongoing processes. This last technique can graph the interactions of team members over time, determining the flow of activities and communication.

Empirical research has established team coordination as an important correlate of team performance. For example, Guastello and Guastello (1998) reported that coordination rules were implicitly learned and then transferred successfully to new rules of similar difficulty. They also noted that team coordination may occur without verbal mediation or leadership actions and that coordination transfer was less positive to a task of greater difficulty. Stout, Salas, and Carson (1994) examined the effects of coordination on two-person team performance on a flight simulation task. Interactive processes that were examined included such behaviors as providing information in advance, making long- and short-term plans, asking for input, assigning tasks, and stepping in to help others. Coordination ratings positively predicted mission performance of the team when individual task proficiency was held constant. Important concerns relevant to future research on coordination center on issues of levels and time. 
With respect to levels, it is important to identify coordinated team responses that represent a broad range of disparate and complex patterns of individual action, and are not simply the sum of the responses of team members. Similarly, it is important to determine when the responses of individuals are part of a coordinated team response, and when they are simply individual responses (Zalesny et al., 1995). Finally, a key issue concerns how to represent interactions of individual team members over time at higher levels of analysis. Recent theoretical work on the nature of emergent constructs-how higher-level phenomena emerge from the characteristics and interactions of individuals - offers some guidance in this regard (Kozlowski \& Klein, 2000). With respect to temporal issues, research must be sensitive to both the context and the temporal elements in which coordination occurs. Most theories assume that coordination is learned: How does it develop and emerge at the team level over time (Kozlowski et al., 1999)?

Cooperation can be defined as "the willful contribution of personal efforts to the completion of interdependent jobs" (Wagner, 1995, p. 152), and is often viewed as the opposite of conflict. Much of the research on cooperation and collaboration has been conducted in social psychology around issues of free riding and social loafing (Latané et al., 1979). This research has focused considerable energy on identifying factors that might eliminate uncooperative tendencies and instead induce cooperation in groups (Kerr \& Bruun, 1983). We discuss such work elsewhere in the chapter in the section on Leadership and Motivation. Cooperation and collaboration have also been examined in the context of culture, specifically in the difference between individualistic and collectivistic orientations.

Research suggests that cooperation is generally associated with team effectiveness. For example, Wagner (1995) reported that individualists are less apt, and collectivists more apt, to behave cooperatively. He also found that individualism-collectivism moderates relationships between group size, identifiability, and cooperation such that group size and identifiability have greater effects on the cooperation of individualists than they do on the cooperation of collectivists. Seers, Petty, and Cashman (1995) found that departments with greater team-member exchange had significantly higher efficiency as captured from archival records. Pinto and Pinto (1990) examined the effect of cross-functional cooperation in hospital project teams and found that cooperation positively predicted both task and psychosocial outcomes, such that teams high in cooperation relied more heavily on informal modes of communication than did low cooperation teams. Finally, Smith et al. (1994) showed that cooperation in top management teams was positively related to return on investment and sales growth.

Most theoretical work that incorporates communication does so in the context of coordination and cooperation. That is, as noted previously, communication is seen as a means for enabling the more 
primary processes of coordination and cooperation. Communication can serve two important functions (Glickman et al., 1987) that aid taskwork and teamwork. Taskwork communication involves exchanging task-related information and developing team solutions to problems. Teamwork communication focuses on establishing patterns of interaction and enhancing their quality.

Research using content analysis has found that differences in communication patterns are related to differences in team performance (e.g., Foushee \& Manos, 1981). Ancona and Caldwell (1992a, 1992b) found that external communication frequency was positively related to team performance. However, external communication was negatively associated with a team's assessment of its overall performance and with member ratings of team cohesion. Ancona (1990) reported that team leader strategies (e.g., probing) affected the types and frequency of external communication. Smith et al. (1994) reported that communication frequency was negatively related to TMT effectiveness, and suggested that greater communication frequency may be indicative of high levels of conflict. Campion et al. (1993) found that communication between teams did not have a significant impact on productivity, member satisfaction, or manager's judgments of team performance. Waller (1999) indicated that frequency of information collection (e.g., request weather information) related to the performance of airline crews.

What are the compelling research issues for team communication? From our perspective, the central issue in team processes concerns the synergistic combination of individual contributions to team effectiveness. Communication is a primary means to enable more proximal factors like coordination and cooperation. Communication is a lens. Thus, research on communication type and frequency can be revealing of what team members are trying to coordinate and how much information they need or how difficult it is to do so. However, focusing solely on communication type and amount in the absence of attention to coordination and cooperation is incomplete. In addition, from a coordination perspective, focusing on just type and frequency ignores timing issues. When requests for information or assistance are made, how quickly others respond, and the timing constraints imposed by the team task are likely to be critical issues in sorting out when communication is and is not helpful for team effectiveness.

\section{Enhancing Team Effectiveness}

Decision Effectiveness. Team decision effectiveness has been the subject of high profile research streams in the 1990s. Sparked by major military catastrophes caused by breakdowns in team coordination processes, this work was undertaken to better understand team decision effectiveness and to develop interventions to promote it. Here we highlight two such efforts. Hollenbeck, Ilgen, and their colleagues (1995) developed a theory of decision making for hierarchical teams with distributed expertise, in which 
team members possess distinctive roles and have access to different decision-relevant information. This allows them to make a decision recommendation that they pass onto a team leader who then renders the team's decision. The research paradigm is temporally sensitive in that the leader makes decisions, gets feedback, and has to incorporate the feedback into subsequent decisions. Hollenbeck et al. (1995) introduced the theory and tested it in two research contexts showing that team leaders are generally sensitive to the quality and accuracy of the advice they receive from team members and, over time, adjust accordingly. Hollenbeck, Colquitt, Ilgen, LePine, and Hedlund (1998) evaluated boundary conditions across different components of decision accuracy and member specialization. Finally, Phillips (1999) examined antecedents of hierarchical sensitivity - a core theoretical construct indicative of the leader's ability to accurately assess the validity of staff members' recommendations.

Cannon-Bowers, Salas, and their colleagues conducted a seven-year multidisciplinary research effort-the Team Decision Making Under Stress (TADMUS) program—that was designed to improve team training and the human factors of interface design for tactical decision-making teams (TDM; Cannon-Bowers \& Salas, 1998). One of the key features of the TADMUS program was its active integration of theory development, basic research, field testing, and application. The program was driven by grounded theory, which was evaluated by basic laboratory research. Promising findings were subject to field testing to ensure generalization to the operational environment. Finally, proven techniques were implemented and institutionalized. In many ways, TADMUS represents an excellent example of the way that theory and basic research can transition to effective organizational application.

Team Competencies and Performance. The relevance of team processes to enhancing team effectiveness is that they are presumed by the IPO framework to be proximal predictors of team performance outcomes. Hence, although there are other strategies relevant for improving team effectiveness - such as influencing the composition of team abilities via selection, or improving processes via team design and leadership_-direct enhancement of team processes via training is the most prevalent team effectiveness intervention (Cannon-Bowers \& Salas, 1997). This strategy necessitates two foci: (1) specifying the competencies that underlie effective team performance and (2) designing and delivering training that improves these competencies, enhances team processes, and increases team effectiveness.

From a criterion perspective, team performance can be defined as a product or outcome of team action that satisfies external constituencies (Hackman, 1987). However, at the more specific level of identifying factors that constitute critical team performance dimensions definitional challenges are encountered. As noted in our discussion of team typologies, it is very difficult to develop a common 
specification of team performance-it varies by the type of team. Constraints emanating from the team's context and its task, and their implications for internal and external linkages, lead to different dimensions of performance being relevant for different types of teams. Thus, team performance specification and measurement must be grounded by the team context and task (Goodman et al., 1987). Rigorous, reliable, and valid measures of team performance are essential tools for enhancing team effectiveness (see Brannick, Salas, \& Prince, 1997, for issues and measurement approaches).

It is also important to appreciate the orientation taken by researchers toward team performance in their efforts to enhance team effectiveness. The orientation has been much more targeted on processes, than outcomes. Rather than treating team performance as a static, retrospective, summary variable intended to capture the outcome of many specific behaviors over an extended period of time, efforts to understand team performance for training purposes have tended to focus on what individuals and teams need to do to perform well. In other words, the focus has been on behaviors that have to be exhibited over time and on the underlying competencies that enable those behaviors. An important issue here is the need to distinguish between team-level performance outcomes, and the individual-level actions and interactions that are the foundation for team-level performance (Kozlowski, Brown, Weissbein, Cannon-Bowers, \& Salas, 2000). In this regard, researchers have generally distinguished between taskwork skills—individual job or technical skills_-and teamwork skills_-knowledge, skills, and attitudes (KSAs) that enable one to work effectively with others to achieve a common goal. Thus, at a general level team performance and teamwork competencies are easy to identify - they are the cognitive, affective/motivational, and behavioral process mechanisms described previously and the KSA's that enable them, respectively. Three relatively comprehensive efforts to identify teamwork competencies are described below.

Fleishman and Zaccaro (1992) describe a taxonomy of team performance functions in an effort to be more specific than previous classifications of group performance tasks. They synthesized seven major categories of team performance functions: (1) orientation (e.g., information exchange regarding member resources and constraints), (2) resource distribution (e.g., load balancing of tasks by members), (3) timing (e.g., activity pacing), (4) response coordination (e.g., timing and coordination of responses), (5) motivation (e.g., balancing team orientation with individual competition), (6) systems monitoring (e.g., adjustment of team and member activities in response to errors and omissions), and (7) procedure maintenance (e.g., monitoring of general procedural-based activities). Note that these performance functions primarily implicate competencies that enhance coordination and cooperation.

Based on their extensive work with aircraft cockpit crews and TDM teams, Salas, Cannon- 
Bowers, and their colleagues synthesized a set of eight teamwork skill dimensions (Cannon-Bowers, Tannenbaum, Salas, \& Volpe, 1995; Salas \& Cannon-Bowers, 1997): (1) adaptability—competency to adjust strategies using compensatory behavior and reallocation of team resources, (2) shared situational awareness - possession of shared/compatible mental models of the team's internal and external environment used to arrive at a common understanding of the team situation and to derive appropriate strategies to respond, (3) performance monitoring and feedback - the capability to monitor teammate performance, give constructive feedback about errors, and make helpful suggestions for improvement, (4) leadership/team management—competencies to plan, organize, direct, motivate, and assess teammates, (5) interpersonal relations-skills to resolve conflict and engage cooperation, (6) coordinationcompetencies to integrate and synchronize task activities with other teammates, (7) communicationcapability to clearly and accurately convey information and acknowledge its receipt, and (8) decision making-competencies to pool, integrate, and select appropriate alternatives and evaluate consequences.

In addition, they have also developed a typology for classifying team competencies and specifying essential knowledge (i.e., facts, concepts, relations), skills (i.e., cognitive-behavioral procedures), and attitudes (affective components of teamwork). The 2 x 2 typology is based on task and team dimensions. Each dimension is further distinguished by whether the competencies are specific or generic, resulting in four distinct classes of competencies appropriate for different types of teams. For example, transportable competencies (task and team generic) generalize across teams and are most appropriate for situations in which individuals are members of multiple project teams. In contrast, context-driven competencies (task and team specific) are appropriate for action teams with tight linkages to a dynamic external environment and complex internal workflows with a strong emphasis on coordination, knowledge of interlinked role demands, and adaptability (e.g., trauma teams, emergency response, TDM teams, aircrews). Specific competencies and KSAs for each of the four cells can then be mapped for different types of teams (Salas \& Cannon-Bowers, 1997).

Based on an extensive review, Stevens and Campion (1994) developed a 35-item measure of the KSAs underlying effective teamwork behavior. Although it has been shown that certain personality traits evidence criterion related validity, these authors concentrated on those KSAs that were more in line with traditional ability-based systems. They also selected attributes solely at the individual level of analysis because their focus was on selecting, training, and evaluating individuals for a team environment, not creating the best combination of team members. Finally, the authors rejected those KSAs that were team or task specific and instead focused on those skills related to the team and task generic component of the 
model proposed by Cannon-Bowers et al. (1995). Their search resulted in a final list of ten interpersonal KSAs and four self-management KSAs. The interpersonal KSAs were then classified further into conflict resolution, collaborative problem solving, and communication KSAs. The self-management KSAs were also separated into two categories: goal setting and performance management KSAs and planning and task coordination KSAs. Work by Stevens and Campion (1994) and others (e.g., Ellis, Bell, \& Ployhart, 2000; McClough \& Rogelberg, 1998) suggest that the measure is a valid predictor of team performance.

Team Training. A variety of direct interventions have been proposed to improve team performance and effectiveness. We touch on a few techniques that have received research attention, but note that this is a huge area of practice-there are literally thousands of interventions. Some form of team building is perhaps the most ubiquitous team training technique, and generally focuses on improving team skills in one or more of four areas (Salas, Rozell, Mullen, \& Driskell, 1999c): (1) goal setting—skills to set and achieve objectives, (2) interpersonal relations-skills to develop communication, supportiveness, and trust, (3) problem solving-skills for problem identification, solution generation, implementation, and evaluation, and (4) role clarification - skills to enhance understanding of others' role requirements and responsibilities. Although there are many testimonials touting the effectiveness of team-building techniques, solid empirical support for their efficacy is weak. A recent meta-analysis (Salas et al., 1999c) indicated no significant overall effect for team building on team performance. There was a small positive effect for subjective measures of performance, but no effect for objective indicators. And, of the four components, only role clarification evidenced any contribution to team performance.

Although team building is oriented toward improving characteristics that emerge naturally during socialization and team development, team building is typically targeted at mature teams that have already developed strong informal structures and normative behavior patterns. It is quite a bit more difficult to change informal structure once it has jelled than to shape it during socialization and development. Thus, we believe that team-building techniques may have more potential for leveraging improvement if applied when team members are more malleable (e.g., Kozlowski et al., 1996b; Kozlowski et al., 1999).

Because of the enormous human and material consequences of team failure, the aviation and military communities have pioneered efforts to improve team effectiveness through training. On the aviation side, some form of Crew Resource Management (CRM) training is in widespread use in both commercial and military aviation. Early CRM training focused on changing the teamwork attitudes of team members, whereas work in the 1990s shifted towards better definition, measurement, and training of team processes. On the military side, the TADMUS program developed and evaluated a variety of 
training techniques designed to improve the effectiveness of military TDM teams (see Cannon-Bowers \& Salas, 1998). Although these are distinctive areas of research, the tasks of aviation cockpit crews and TDM teams share many underlying commonalities and, as a consequence, key processes essential for team effectiveness and methodologies to design and deliver training exhibit a high degree of overlap across both areas. Key processes are defined by the eight dimensions of teamwork (described above; Salas \& Cannon-Bowers, 1997). Similarly, there is overlap in training techniques employed in both areas. Salas and Cannon-Bowers (1997), for example, identify six general training strategies for enhancing team processes and other essential KSAs: (1) task simulations-as a means to develop accurate performance expectations for various task demands, (2) role plays and behavior modeling-for building compatible KSAs, (3) team self-correction - in which team members monitor each other and provide corrective feedback, (4) team leader training - in which the leader guides the team through the self-correction process, (5) cross training - to instill crucial knowledge about the behavior and information needs of one's teammates, and (6) teamwork skill training-to provide generic teamwork skills when members must work on across a variety of tasks or on many different teams. Research from TADMUS and extensive work on CRM provides an empirical foundation supporting the efficacy of these techniques.

Although research on team training will continue to advance, these systematic efforts to identify key team competencies (Salas \& Cannon-Bowers, 1997), develop appropriate performance assessment technologies (Brannick et al., 1997), apply structured methodologies to design training (e.g., Salas et al., 1999b), and evaluate training effectiveness (e.g., Salas, Fowlkes, Stout, Milanovich, \& Prince, 1999a) provide a model for team training research and practice for other types of teams.

Issues for Future Research on Team Training. We close this discussion on the use of training to enhance team effectiveness by identifying issues that need to be carefully considered in future research, organized around three themes: (1) what to train, (2) when to train, and (3) how to train. What to train? There has been considerable progress in the 1990s on identifying important teamwork competencies and specifying their underlying KSAs. We note that virtually all of this work has been conducted on action teams that place the most complex and challenging demands on teamwork skills. The big question that remains is to what extent do these competencies — presumably in some modified form - apply to other types of teams that have much weaker demands for temporal entrainment and coordination? Thus, a key research issue is the generality of the competencies to other team types. A related issue concerns the assessment of team performance. Many research assessments rely on extensive observation during complex simulations or in-context performance (see Brannick et al., 1997). However, assessing individual 
and team contributions to team effectiveness in organizational environments is plagued by all of the problems that beset individual-level performance appraisal. This area is under researched.

When to train? As we noted previously, much team training is "remedial," targeted on mature teams rather than during team socialization and development when team members are more malleable and training can exert more leverage. There are well-developed descriptive (Morgan et al., 1993) and normative (Kozlowski et al., 1996a, 1996b, 1999) models that specify developmental phases where particular competencies are likely to be most pertinent to trainees and more malleable to the influence of interventions. However, there has been relatively little research to examine the efficacy of shifting the target of training to track developmental progress. DeShon et al. (2001) provide promising evidence that shifting regulatory focus from individual to team contributes to enhanced team performance adaptability. We believe that this area represents a research issue with the potential for considerable practical gain.

How to train? The development and evaluation of new techniques will likely continue to capture the attention of many researchers and practitioners. Emerging technologies are making it increasingly possible to push team training out of the classroom and into the workplace, making it more contextually grounded and resolving the ever present gap between training and skill transfer. With the increasing penetration of computers into the workplace, we will witness the growth of web-based training, distance and distributed training, distributed interactive simulations, and other tools that take advantage of increased computing power, low cost, and enhanced connectivity. However, it is important to remember that these new tools are merely delivery media. How to use these advanced tools to good instructional effect is the critical research issue (Kozlowski, Toney, Mullins, Weissbein, Brown, \& Bell, 2001).

A final issue concerns the level at which training should be delivered-individuals or intact teams? Much "team" training is really targeted on individual skill building. Can individual training improve team effectiveness? Focusing on the issue of vertical transfer (i.e., the extent to which individual actions propagate upwards to influence team performance), Kozlowski and colleagues (Kozlowski \& Salas, 1997; Kozlowski et al., 2000) have argued that the nature of the teams' task should dictate the mode of delivery, individual or team. When team-level performance is based on compilation processesworkflows that emphasize distributed expertise, temporal entrainment, and synchronous coordinationtraining should be delivered to intact teams in actual performance settings (or very close approximations) because of the emphasis on integrating disparate actions. In contrast, when team-level performance is based on composition processes — workflows that emphasize additive individual contributions — training should be targeted at the individual-level because it is more efficient and cost effective. Research on this 
issue is virtually non-existent, and represents an opportunity to refine team training delivery models.

\section{TEAM LEADERSHIP AND MOTIVATION}

$\underline{\text { Team Leadership }}$

Most models of team effectiveness recognize the critical role of team leaders. Although there is certainly no shortage of leadership theories, examining this extensive literature is beyond the scope of this chapter (see Yukl \&Van Fleet, 1992 for a comprehensive review). However, at the onset we note that the focus of many leadership theories is on traits, such as intelligence and originality (Bass, 1981; Fiedler, 1989), or on the frequency of leader's activities, such as telephone calls and scheduled meetings (McCall, Morrison, \& Hannan, 1978). Relatively neglected is what leaders should actually be doing to enhance team effectiveness - their functional role - a perspective that we believe is more productive. In addition, many leadership theories focus on the individual level; there are relatively few attempts to examine the differences between leading in the team context and leading individuals. In this section, we examine the functional role of team leaders and discuss how leadership functions are sometimes shifted to team members through self-management. We conclude with practical recommendations for leading teams.

Functional Role of Team Leaders. Although there have been only a few efforts to specify the functional role of team leaders, there is reasonable consistency in the important leadership functions that need to be accomplished. Different labels have been used to describe these functions, but they can be grouped into two basic categories: (1) the development and shaping of team processes, and (2) the monitoring and management of ongoing team performance (Fleishman et al., 1991; Hackman \& Walton, 1986; Komaki, Desselles, \& Bowman, 1989; Kozlowski et al., 1996a, 1996b; McGrath, 1962).

With respect to team development, leaders are often faced with the challenge of building a new team. In these situations, a leader's functional role is to develop individuals into a coherent, seamless, and well-integrated work unit (Kozlowski et al., 1996a). In other instances, teams experience personnel outflows and inflows over time. As new replacement personnel are brought into the team, they need to be socialized and assimilated (Moreland \& Levine, 1989). Leaders are critical to this newcomer assimilation

process (Ostroff \& Kozlowski, 1992). Developmental functions of team leaders focus on the enactment of team orientation and coaching to establish team coherence (Kozlowski et al., 1996a). Team orientation includes factors with motivational implications, such as promoting shared goal commitment, creating positive affect, and shaping climate perceptions. Team coherence includes the development of linked individual goals, a repertoire of team task strategies, and compatible team member role expectations. The leader's developmental role is to establish and maintain coherence and integration among the members of 
the unit. Coherence then allows team members to self-manage during periods of intense task engagement.

A second major functional role of team leaders is to establish and maintain favorable performance conditions for the team. In this capacity, leaders engage in two types of behavior: monitoring and taking action (Hackman \& Walton, 1986; Kozlowski et al., 1996a, 1996b; McGrath, 1962). Monitoring involves obtaining and interpreting data about performance conditions and events that might affect them. Monitoring functions include vigilance, diagnosing group deficiencies, data gathering skills, forecasting impending environmental changes, and information use in problem solving. For example, an effective leader will monitor whether the team has adequate material resources and will also forecast potential resource crises. Leaders also need to collect performance information and provide feedback. In doing so, they make team members aware of the consequences of their behaviors. When problems are discovered, leaders must gather information to determine the nature of the problem and take action to devise and implement effective solutions. A leader's actions can be designed to improve the present state of affairs, exploit existing opportunities, or to head off impending problems. Specific actions can include clarifying the direction of the team, strengthening the design of the group or its contextual supports, providing coaching or process assistance, or ensuring the group has adequate resources (Fleishman et al., 1991; Hackman \& Walton, 1986; Komaki et al., 1989; Kozlowski et al., 1996a, 1996b; McGrath, 1962).

One important characteristic underlying these theoretical efforts to identify the key functional roles of team leaders is the assumption that the leader interacts directly with team members in the processes of team development and performance management. However, this assumption may not always hold true, especially with today's advanced technologies and the capability to have virtual teams composed of members who are spatially and temporally distributed (Bell \& Kozlowski, in press). In these environments, it may be necessary for teams to manage themselves in the absence of a formal leader. Considerable research has focused on self-managing teams, which we review in the next section.

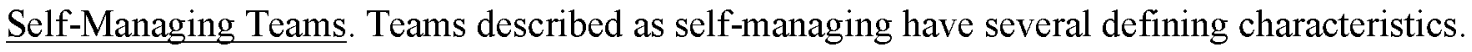
They are given relatively whole work tasks and are allowed increased autonomy and control over their work (Hackman, 1986; Manz, 1992). In addition, the members of such teams are responsible for many traditional management functions, such as assigning members to various tasks, solving within-team quality and interpersonal problems, and conducting team meetings (Lawler, 1986). Self-managing teams often have leaders; however, their primary function is to enable self-management.

Many benefits have been attributed to self-managing teams, including increased productivity, quality, and improved quality of work life for employees, as well as decreased absenteeism and turnover 
(Cohen \& Ledford, 1994; Lawler, 1986; Manz \& Sims, 1987). Although research suggests that selfmanaging work teams can be quite effective (Neck, Stewart, \& Manz, 1996; U.S. Department of Labor, 1993), they sometimes fail. It has been suggested that these failures are often linked to the behaviors of team leaders. For example, teams with leaders who are too actively involved in the team's activities or who are too autocratic may not develop a sense of autonomy and may feel powerless (Stewart \& Manz, 1995). It has been suggested that the optimal leader for self-managing teams is one who displays passive involvement in the team's activities and a democratic power orientation. Such leaders lead through modeling and assisting, helping the team to develop self-direction and ownership for activities.

Recent research also suggests that the social context within a team and the team's task may moderate the effectiveness of self-managing teams. For example, Tesluk, Kirkman, and Cordery (2001) found that self-leadership resulted in greater autonomy in work units that displayed a less cynical orientation toward change efforts. In work groups that had a more cynical attitude toward change efforts, a self-leadership management style had little impact on perceptions of team autonomy. Stewart and Barrick (2000) found that for teams engaged primarily in conceptual tasks, team self-leadership exhibited a positive relationship with performance. In contrast, for teams engaged primarily in behavioral tasks, there was a negative relationship between self-leadership and performance. However, the mechanisms underlying these differential effects were unclear and should be examined in future work.

Practical Applications. Research and theory on leadership has been conducted at multiple levels of analysis. While some theories focus on specific characteristics of leaders or their followers (e.g., Bass, 1981), other theories such as leader-member exchange (LMX), focus on the dyadic relationships between a leader and a member (e.g., Dansereau, Graen, \& Haga, 1975), and still other theories focus specifically on leadership in team contexts (e.g., Hackman \& Walton, 1986; Kozlowski et al., 1996a, 1996b). Although the focal level differs across these theories, many of them provide recommendations that are presumed to be applicable in team settings. Indeed, many of the leader characteristics (e.g. intellectual stimulation, consideration) and leader-member exchange patterns (e.g., delegation) that have been shown to be effective in leading individuals should also be effective for leading individuals in the team context.

It is important, however, to recognize that team environments create a number of unique challenges for leaders. For example, team leaders must focus not only on developing individual skills but also on promoting the development of teamwork skills that underlie coordination, such as mutual performance monitoring, error detection, load balancing, and resource sharing (Kozlowski et al., 1996a). Team leaders also must guide the development of a collective, team-level efficacy, or the belief that the 
team can work together effectively to accomplish the task or goals set before it (Campion et al., 1993; Shea \& Guzzo, 1987). Team leaders can also be instrumental in developing effective team mental models (Klimoski \& Mohammed, 1994). Marks et al. (2000), for example, found that leader briefings that highlighted task strategies affected the development of team mental models, which in turn positively influenced team communication processes and team performance.

It is also important for team leaders to tailor their behavior based on the team's environment and task. The research discussed above by Stewart and Barrick (2000), for example, suggests that leaders should promote different levels of self-leadership depending on the team's task. Leaders may also need to adopt a different role when faced with the challenge of leading a virtual team. In these situations, it is often very difficult for leaders to monitor the performance of team members due to spatial and temporal separation. As a result, it may be critical for virtual team leaders to clearly define the team's objective, facilitate team members' understanding of their responsibilities, and create explicit structures that help the team manage its performance (Bell \& Kozlowski, in press; Cascio, 2000).

\section{$\underline{\text { Team Motivation }}$}

The majority of theory and research on motivation has been focused at the individual-level. In fact, relatively little research has specifically examined motivation as it operates in team contexts or at the team-level. Much of what we know about motivation in team contexts comes from research in the field of social psychology that has examined the productivity or process loss that often occurs when individuals work in groups. Although much of this work focuses on individual motivation and performance in the group context-not on team motivation and performance per se, researchers frequently extrapolate effects to the team level. Moreover, as we discuss below, many of these findings may not apply to teams as they typically exist in organizational settings, suggesting that researchers need to focus greater attention on the issue of motivation in work teams. In the following section, we provide a brief review of research on productivity loss in teams. We then examine some theories that have focused specifically on motivation in teams, and conclude with practical recommendations for motivating teams.

Productivity Loss. A large body of research has shown that individuals tend to exert less effort when their efforts are combined rather than individual. This effect, referred to as social loafing, and similar phenomena (e.g., free-rider and sucker effects) are considered to be robust and to generalize across tasks and work populations (Karau \& Williams, 1993). However, research has also shown that there are numerous variables that moderate the tendency to engage in social loafing. For example, social loafing can be eliminated by having individuals work with close friends, increasing the identifiability of 
individual contributions, and providing clear performance standards. In fact, research suggests that many of the variables that eliminate social loafing also serve to enhance team performance. This effect is known as social facilitation, which results from the motivation to maintain a positive self-image in the presence of others, particularly when others are viewed as potential evaluators (Zajonc, 1965).

Research on social loafing and social facilitation have developed independently and offer rather conflicting views on the motivational effects of individuals working in teams. This apparent discrepancy, however, may be explained by the fact that traditional research on social loafing has often been conducted in artificial groups that do not conform with the definition of groups as involving individuals' mutual awareness and potential mutual interaction (McGrath, 1984). These studies have typically used pooled tasks in which team members provide independent and unidentifiable contributions to the team's performance. Recent research, however, has found that characteristics of teams in work organizations, such as team member familiarity, interaction, and communication, eliminate social loafing and may actually lead to social facilitation (Erez \& Somech, 1996). Thus, the extent to which social loafing and related effects are important motivational phenomena in the context of work teams is open to question.

Theories of Team Motivation. Compared to research on individual-level motivation, relatively little work has directly considered the issue of motivation in teams. Indeed, there are no well-developed motivation theories that explicitly incorporate the team-level. What is interesting, however, is that much of the work on this topic has focused on the issue of aligning individual-level and team-level sources of motivation. Weaver, Bowers, Salas, and Cannon-Bowers (1997), for example, differentiated between individual-level motivation, referred to as taskwork motivation, and team-level motivation, referred to as teamwork motivation. They argued that team performance is enhanced when these individual-level and team-level sources of motivation are not only congruent with one another, but also with the goals of the organization (Saavedra, Early, \& Van-Dyne, 1993).

Research on goals, feedback, and rewards has also considered congruence among individuallevel and team-level sources of motivation. It has found that group goals, in addition to or instead of individual goals, are necessary or at least facilitative when the task is a group rather than an individual one (Matsui, Kakuyama, \& Onglatco, 1987; Mitchell \& Silver, 1990). Research also suggests that it is important for team members to receive individual and team level performance feedback (DeShon, Kozlowski, Wiechmann, Milner, Davis, \& Schmidt, 2000; Matsui et al., 1987). Team feedback by itself is problematic when the good performance of one team member can compensate for the poor performance of a teammate (Salas et al., 1992). People performing poorly who only receive team feedback may not 
attempt to improve their performance if the team is succeeding. Finally, research suggests that the relative effectiveness of team-based, as compared to individual-based, rewards may depend on several factors, such as the degree of team interdependence (Wageman, 1995) and the characteristics of team members (e.g., individualism-collectivism; DeMatteo, Eby, \& Sundstrom, 1998; Kirkman \& Shapiro, 2000).

Overall, research suggests that individual-level and team-level sources of motivation should be congruent with one another, and with other features of the organizational context. Despite these findings, we know relatively little about how motivation operates at the team-level. Research has often produced mixed findings or has failed to examine potentially important contingency variables. As DeMatteo et al. (1998, p. 152) state in their review of team-based rewards, "Despite hundreds of studies examining group rewards, the conditions under which team rewards will be effective are unclear." To advance understanding, a multilevel theory of motivation is needed that will guide future research and serve as a tool for integrating and interpreting relevant research findings. Because the promising work in this area involves constructs relevant to models of regulatory activity (i.e., goals, feedback), we believe that a multilevel model of self- and team-regulation has the potential to provide this integration.

Practical Recommendations. Several authors have offered recommendations for enhancing team motivation. Sheppard (1993), for example, suggested that lost productivity can arise in teams when any one of the following three conditions is present: individuals perceive no value to contributing, perceive no contingency between their contributions and achieving a desirable outcome, or perceive the costs of contributing to be excessive. To overcome these effects, Sheppard (1993) provided three categories of solutions that correspond to each of the three sources of productivity loss. These include providing incentives for contributing, making contributions indispensable, and decreasing the costs associated with contributing, respectively. The Productivity Measurement and Enhancement System (ProMES; Pritchard, Jones, Roth, Stuebing, \& Ekeberg, 1988) is a concrete example of how group-based feedback, goal setting, and incentives can be used to reduce productivity loss and enhance team performance.

Rewards and incentives, examined mainly in service teams, are among the most frequently studied factors designed to enhance team motivation in organizations. Effects for rewards have been mixed. Several studies have found that rewards have no significant relationship with team effectiveness (e.g., Campion et al., 1993; Gladstein, 1984), although a few studies have found rewards to have positive effects under certain conditions (Wageman, 1997). Wageman (1995) found that service technician groups with low task interdependence performed best with individual-based rewards, but groups with high interdependence performed best with group-based rewards. Pritchard and colleagues (1988) also found 
that incentives lead to a small increase in team productivity, although their ProMES intervention produced more substantial increases. Finally, Cohen, Ledford, and Spreitzer (1996) found that a nonmonetary reward, recognition by management, was positively associated with team ratings of performance, trust in management, organizational commitment, and satisfaction for both self-directed and traditionally managed groups in a telecommunications company. Overall, there is some evidence to suggest that group-based rewards can increase team effectiveness. However, research is needed to further examine the role of contingency variables, such as task structure and team composition, in the relationship between reward systems and work team effectiveness (DeMatteo et al., 1998).

Swezey and Salas (1992) conducted a review of research on individuals within teams or groups and identified several prescriptive guidelines that have relevance to team motivation. They offered several concrete suggestions for motivating teams, such as employing positive reinforcement techniques and developing a system of rewards for those who exhibit supportive behaviors toward teammates. As discussed above, research has tended to show that team performance is enhanced when goals, feedback, rewards, and task interdependence requirements are congruent with one another. Thus, to enhance team motivation, an organization should ensure that the work context is configured so that individual and team motivation are aligned and do not contradict each other.

\section{Team Viability}

\section{CONTINUANCE AND DECLINE}

Team effectiveness has often been defined as the quantity and quality of a team's outputs (e.g., Shea \& Guzzo, 1987). This definition, however, overlooks the possibility that a team can "burn itself up" through unresolved conflict or divisive interaction, leaving members unwilling to continue working together (Hackman, 1987, p. 323). Thus, some researchers have argued that definitions of team effectiveness should also incorporate measures of team viability (Guzzo \& Dickson, 1996; Sundstrom et al., 1990). Team viability refers to members' satisfaction, participation, and willingness to continue working together in the future. It can also include outcomes indicative of team maturity, such as cohesion, coordination, effective communication and problem-solving, and clear norms and roles (Sundstrom et al., 1990). The major issue, however, is whether a team can sustain effective levels of performance over time.

Relatively little is known about long-term team viability, although theory (Katz, 1980) suggests that team continuance has a curvilinear relationship with team performance: team effectiveness initially improves with time, but declines with increasing group age. Katz (1982) suggests that decline begins two to three years into a team's existence. Research on R\&D teams suggests that effectiveness peaks between 
2-3 (Katz \& Allen, 1988) and 4-5 years of group age (Pelz \& Andrews, 1966), with marked decline after 5 years (Katz \& Allen, 1988). Other work suggests decline as quickly as 16 months of group existence (Sheppard, 1956). While the mechanisms that cause team performance to fade over time are not well understood, several explanations have been offered. Hackman (1992) suggests that the increased cohesiveness that develops over time may lead to groupthink and other negative outcomes associated with the rejection of dissenting opinions. Continuance also tends to increase team member familiarity. It has been argued that familiarity may be beneficial early in a team's existence, by fostering rapid coordination and integration of team members' efforts (Cannon-Bowers et al., 1995). However, familiarity may eventually become a liability as the lack of membership change contributes to stultification and entropy (Guzzo \& Dickson, 1996). Similarly, Katz (1982) has suggested that communication within and between teams declines as teams age. Katz and Allen (1988), who examined 50 R\&D teams, provided support, showing that declines in communication were associated with effectiveness declines over time. Importantly, they also reported that the greatest communication decay was in those areas most central to team activities (e.g., for technical service teams, intra-team communication; for project teams, external communication). Thus, team communication appears to an important mediator of the effects of team continuance on team effectiveness. Additional research is needed to examine team viability over significant periods of time, and to identify factors that can promote it.

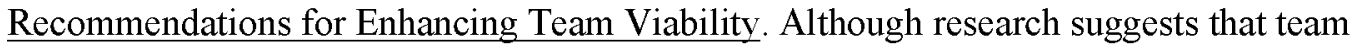
performance deteriorates given enough time, it may be possible to combat this trend. West and Anderson (1996) show that four factors-vision, participative safety, task orientation, and support for innovationdefine a climate that predicts team innovativeness. It is also important for organizations to assess whether a group is using the energy and talents of its members well (rather than wasting or misapplying them), and to determine whether group interaction patterns that develop over time expand (rather than diminish) members' performance capabilities. For example, it has been suggested that while cohesion is detrimental when it is social or interpersonal in nature, it may be beneficial when it is task-focused (Hackman, 1992). Team goals and rewards may be used to facilitate task-based cohesion (Zaccaro \& Lowe, 1988), or interventions may be developed to maintain team communication over time.

Teams should also be provided ongoing assistance throughout their lifecycle. Hackman (1987) suggests that this assistance can come in three forms. First, teams can be provided opportunities to renegotiate aspects of their performance situation. Second, process assistance should be provided as needed to promote positive group synergy. For example, it may be important to manage personnel inflows 
and outflows over the course of a team's lifecycle. Just as stable membership can lead to dullness and entropy, the introduction of new members - properly managed - can renew and revitalize a team. And third, teams should be provided opportunities to learn from their experiences.

Finally, it may be possible to influence team viability through the selection of team members. Barrick et al., (1998) found that teams that have greater cognitive ability, are more extraverted, and are more emotionally stable are more likely to stay together in the future. They also found that the effects of extraversion and emotionally stability on team viability were mediated by social cohesion. Teams that were more extraverted and emotionally stable had more positive group interactions, thus becoming more socially cohesive, which in turn enhanced the team's capability to maintain itself (Barrick et al., 1998). Clearly, the issue of team viability can benefit from additional research attention.

\section{RESEARCH ISSUES AND RECOMMENDATIONS}

At the beginning of this chapter, we noted that there was a wealth of material on work groups and teams in organizations. We have endeavored to cover the essence of the most relevant material in this review, and have identified a multitude of issues in need of research attention. In this final section, we highlight what we regard as the major issues that ought to shape future work in the area. We begin with a reconsideration of our four themes—context, task interdependence, levels, and time- to provide a framework for a discussion of general theory and research issues. We then close with more specific recommendations for new research organized around the major topics addressed in the review.

\section{$\underline{\text { Research Issues }}$}

Context. One of the key distinguishing characteristics of the organizational perspective on work groups and teams is appreciation of the fact that they are embedded in a broader system that sets constraints and influences team processes and outcomes. Yet, as one looks across this literature, it is clear that the effects of top-down, higher-level contextual factors on team functioning are neglected research issues. The importance of contextual influences is explicitly recognized theoretically-virtually every model of team effectiveness incorporates organizational contextual factors-yet context is not well represented in research. Beyond theoretical influences, we know relatively little about the effects of the organizational context on team functioning.

Context is also relevant as a product of bottom-up processes. That is, individual team membersby virtue of their cognition, affect, behavior, and mutual interaction processes-enact structural features (e.g., norms, expectations, roles) that serve as team generated contextual constraints. Again, contextual enactment is well-represented in theory, but represents just a small portion of the research base. For 
example, the strong influence of normative expectations on team functioning is an accepted truism in the literature, but knowledge of how such expectations develop is sketchy. There is relatively little work examining the formation of these bottom-up constraints (e.g., Bettenhausen \& Murnighan, 1985).

We think that the field's relative lack of knowledge in this area is due in part to the prevalence of laboratory research on team effectiveness. This observation is not intended as a criticism of laboratory research on teams per se. Appropriately targeted, laboratory research has and will continue to contribute much to our understanding of teams. However, it must be acknowledged that laboratory research, because of its synthetic nature, can contribute to our understanding of contextual influences in only very limited ways. Decomposing the effects of context is really the province of field research with its access to contextually rich research settings. Unfortunately, when contextual effects have been examined in field research on teams, there has been a tendency to focus on the effects of indirect support factors as opposed to more direct linkages to the organizational system. In other words, research has tended to conceptualize team contextual factors in terms of the provision of training or availability of rewards (e.g., Cohen \& Bailey, 1997), which we would expect to be supportive of team functioning, instead of direct system linkages such as technology, structure, and other factors relevant to workflow input-output linkages. Yet, it is these latter factors that are most likely to operate as major constraints on team structure and process

Team research needs to incorporate the effects of major organizational context factors specified in models of team effectiveness.

Task Interdependence. Recognition of the central importance of team task interdependence to team structure and process is a second key characteristic of the organizational perspective on work groups and teams. For the most part, this appreciation is reasonably well represented in both theory and research which generally regard task interdependence either as a critical boundary condition or a moderator of effects (Saavendra et al., 1993; Wageman, 1999). Given its demonstrated importance, new research that fails to consider the effects of task interdependence for the team phenomenon in question has little relevance to building knowledge in the work groups and teams literature. It is a feature that should be explicitly addressed - either as a boundary condition or a moderator - in all work on groups and teams.

We applaud the general recognition of the importance of task interdependence, but assert that this focus only gets at half of the problem-intra-team linkages. We believe that research also has to attend to external system linkages, and how the interface with relevant external factors affects intra-team linkages. In other words, external linkages to broader contextual demands such as goals, temporal pacers (deadlines), and environmental inputs can influence team internal interdependences. Moreover, task 
demands and related interdependencies are not necessarily steady states. Tasks can be conceptualized as episodic (Marks et al., 2001) and cyclical (Kozlowski et al., 1996a, 1996b), making the nature and form of internal interdependencies dynamic and unpredictable (Kozlowski et al., 1999).

Theorists and researchers need to be more sensitive to external influence on task interdependencies and to the dynamics and variations of task interdependencies.

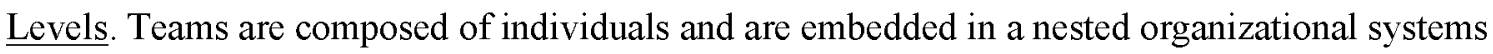
structure. Teams do not think, feel, or behave; individuals do, but individuals think, feel, and behave in an interactive context that can shape their cognition, affect, and behavior such that it has emergent collective properties. These emergent properties evolve over time and are further constrained by higher-level contextual factors. A key implication of this organizational systems conceptualization is that team function and process must be regarded as multilevel phenomena (Kozlowski \& Klein, 2000).

A multilevel conceptualization of team phenomena means that theory and construct definition, measurement procedures, and data analyses must be consistent with principles drawn from the levels of analysis perspective (Kozlowski \& Klein, 2000). A levels perspective necessitates that constructs, data, and analyses be aligned with the level to which conclusions are to be drawn. For much of the research in this area, that level is the team. Yet, many studies that draw generalizations to the team level assess data or conduct analyses at the individual level. Such generalizations are flawed. In other instances, studies assess data at the individual level but aggregate to the team level in order to conduct analyses and draw conclusions. When this aggregation process is properly guided by a model of higher-level composition (Chan, 1998) or emergence (Kozlowski \& Klein, 2000), we can have high confidence in the construct validity and meaningfulness of the higher-level construct that results from the process. When done improperly, that is, with no validation of the underlying model for data aggregation, the result is misspecified constructs, faulty analyses, and flawed generalizations.

A very common example of this flawed procedure (names have been omitted to protect the guilty!) is to collect perceptions from individuals about team characteristics and then to blindly average the individual responses to create team level representations. It is not the use of averages per se that is problematic. As long as conclusions regarding such aggregated characteristics are explicit about the fact that they are "averages of individual perceptions," there is no problem. However, researchers frequently treat averaged variables created by blind aggregation procedures as team-level constructs, imbued with parallel meaning drawn from their individual level origins. This is a major flaw. Treating an average of individual perceptions as a team level construct necessitates a theoretically driven justification. For 
averaged measures, this justification is generally based on an assumption that team members have shared perceptions of the characteristics in question. Sharedness is evaluated prior to aggregation by showing restricted within group variance on the characteristics, thereby establishing the construct validity of the aggregated measure. In the absence of such careful procedures, many "team-level constructs" present in the literature lack the meaning attributed to them. The example described above represents merely one model that may guide aggregation procedures. Other theoretically driven procedures are necessary for higher-level constructs that conform to alternative models of emergence (Kozlowski \& Klein, 2000).

\section{Research on team phenomena must be cognizant of and consistent with the principles of} multilevel theory, data, and analyses.

Time. Despite McGrath's persistent calls for greater attention to time in team theory and research, it is perhaps the most neglected critical issue in this area. It is, with few exceptions, poorly represented in theory and is virtually ignored in research that is largely based on cross-sectional methodologies. Temporal concerns are most prominent in the area of team development-where time is generally viewed as a simple linear progression, but it is vitally relevant to all phases of team processes and performance. Theorists are beginning to become more sensitive to the effects of time across a broader range of team phenomena. For example, time is an explicit factor in McGrath's (1991) TIP model, Kelly et al. (1990) describe how temporal entrainment can pace and cycle team processes, and McGrath (1997) makes a persuasive case for the need to conceptualize team effectiveness as a dynamic and adaptive process-not a static outcome. Kozlowski and colleagues (1999) construct a model of team effectiveness that explicitly addresses developmental progression (i.e., linear time) and dynamic variation (i.e., cyclical entrainment) in the intensity of team tasks. The model considers implications for the emergence of team processes and development of flexible, adaptive teams. Similarly, Marks et al. (2001) develop a temporally based theory of team processes. In their model, team performance emerges from episodic processes comprising transition-action sequences that unfold over time. We believe that these and other models are beginning to provide a sophisticated and expanded conceptualization of temporal impacts on team function and process. Such models provide guidance and points of departure for further efforts.

Why is time so neglected in research? We do not have a definitive answer to this question, but suspect that pragmatic challenges have worked to relegate time to low priority when researchers make the inevitable tradeoffs in data collection design. The challenge for addressing time in laboratory research is that the time frame is limited in duration. It is a commonly held belief that meaningful developmental processes or emergent phenomena cannot occur and be detected in the short duration of the typical 
laboratory experiment. So, why bother? We think such beliefs are misguided. Many important team phenomena such as the initial establishment of norms (Bettenhausen \& Murnighan, 1985), the effects of leaders (Marks et al., 2001), and the influence of regulatory focus (DeShon et al., 2001) can develop very quickly and exert persistent effects over time (Kelly et al., 1990). A focus on carefully targeted team phenomena - those that are expected theoretically to get established early and unfold quickly—can help the field to begin mapping the implications of temporal processes on team development and functioning. Similarly, the challenge for addressing time in field research is the necessity to extend data sampling over time, with consequent effects on sample attrition. Getting access to good field samples is always difficult; getting access over time compounds the challenge. Although cross-sectional designs are clearly more efficient, they by necessity can only treat temporally relevant phenomena like "team processes" as a box-a static representation of the essence by which teams create collective products. Longitudinal designs, though less efficient, will be far more revealing of the team phenomenon under investigation.

Team theory and research should explicitly address the implications of time for team phenomena.

\section{$\underline{\text { Research Recommendations }}$}

As we covered substantive topics in this chapter, we identified a large number of issues in need of specific research attention to resolve conceptual and/or application ambiguities. We have no intention to summarize each of those recommendations. Rather, in this last section, we highlight what we consider to be the more important issues that should shape future research on work teams in organizations.

The Nature of Teams. Organizational teams come in a wide range of varieties, with new forms being developed all the time. Such diversity illustrates the vibrancy of the team as a primary form of work organization, but it also creates challenges. Diversity in the nature of teams has made it difficult to develop useful general models and interventions applicable to all teams. Thus, it is vital that researchers identify the boundary conditions and critical contingencies that influence team functioning and processes for different types of teams. To accomplish this, we believe that researchers need to focus less attention on descriptive classification and more attention to the underlying dimensions and characteristics that are responsible for distinguishing different types of teams. There is relatively little theoretical value in efforts to create a team typology that does not also surface the factors responsible for differential classification. Moreover, identifying the underlying characteristics that distinguish different types of teams will help make more salient the contingencies that determine effectiveness across team types. This will enable both theoretical advances as well as better targeted interventions for enhancing team effectiveness.

Composition. Historically, research on team composition has tended to focus on manifest or 
descriptive characteristics—size and demographics. More recently, team researchers have started to examine team composition in terms of latent constructs - ability and personality. These lines of research have been largely independent. We believe that there is potential value from an integration of these areas. Demographic composition has demonstrated effects, but it is difficult to imagine that such effects occur without mediation by psychological characteristics. Combining these areas may help researchers better focus on identifying mediating characteristics relevant to both types of composition factors. Relatedly, composition research would benefit from more attention to contextual moderators that affect the composition-outcome linkage. In addition, the levels of analysis perspective can be profitably applied to this area of work. Indeed, it must be more prominently applied because a significant portion of team composition research neglects many basic principles of multilevel theory.

Understanding how to compose better teams is the key to leveraging selection as a tool for enhancing team effectiveness. Conventional selection methodology, with its focus on the individual as opposed to the team level, generally promotes a "more is better" perspective when applied to the team level: If conscientiousness promotes better individual performance, then greater collective conscientiousness must be better for team performance. However, as we discussed previously with respect to levels issues, whether this assumption is true or not is dependent on the way in which the construct emerges at the team level: What is the meaning of team conscientiousness in the context of the team task? If it is additive, more is better. But, if it is configural, we need to identify the pattern or configuration of characteristics that create synergy in the team collective. We think that this ideatheoretically, empirically, and practically_is an interesting, exciting, and compelling research issue.

Formation, Socialization, and Development. Existing teams experience personnel outflows and inflows, necessitating a socialization process to acculturate newcomers to the existing informal structure. In other situations, teams are formed anew, necessitating a developmental process wherein all team members simultaneously contribute to the formation of informal structure. Although these are distinctive processes and literatures, we believe that there are parallels that allow the two literatures to mutually inform. For socialization, the primary issue is that research needs to be far more attentive to the effects of the work group on the process of individual socialization. Currently, the work group is viewed as one among many factors that affect the process rather than as the primary locus of socialization. In addition, although socialization theory conceptualizes the process as bi-directional, research typically examines it as unidirectional. Research needs to better capture processes by which the newcomer assimilates to the group, as well as processes by which the group accommodates to the newcomer. We need to better 
understand what insiders can do to facilitate socialization, and then train them to do so.

With respect to team development — research is needed! Although a useful foundation is provided by classic stage models (e.g., Tuckman, 1967), we believe that there is a need to validate and extend newer models that have been specifically formulated for work teams. For example, Gersick's (1988) PEM was derived from descriptive data based on just eight project teams. Although there has been some research to evaluate the PEM and compare it with other models of group development (see Chang et al., in press), there is relatively little work of this type and it tends to be limited to small sample sizes. The PEM has not been subjected to empirical substantiation on a large set of teams, nor on a diverse sample of team types. Although we believe that temporal entrainment is important to team development, we do not believe that it will manifest as a uniform punctuated equilibrium in all types of teams. Indeed, research indicates that the punctuated equilibrium transition can be quite variable (Chang et al., in press), suggesting that other factors influencing temporal entrainment may be operating (Kelly et al., 1990). This would seem to be an important concern, but has received no real research attention. Similarly, Morgan et al. (1993) have some limited evidence in support of their model, but only from a small sample of teams. Kozlowski et al. (1999) synthesized a broad literature base for their normative model to support the content, processes, and outcomes they proposed were relevant at different phases of development. However, efforts to examine model prescriptions are still preliminary (DeShon et al., 2001). If supported, the model was designed to provide a prescriptive foundation for creating interventions that would promote team development as all phases of the team lifecycle. Thus, we assert that solid empirical research to validate, compare, and extend models of work team development is needed.

Team Effectiveness, Processes, and Enhancements. The critical focus of team effectiveness research has been on team processes that link team resources to team outcomes. Thus, conceptualizing team processes and developing interventions that enhance them have been dominant themes in this area. We organized our review around cognitive, affective/motivational, and behavioral process mechanisms.

One of the biggest challenges in the cognitive domain is the necessity to clearly disentangle team mental models, transactive memory, and team learning. Of the three areas, the team mental model literature is arguably the best developed in terms of conceptualization, measurement, and demonstrated effects. Although more work is clearly needed, this research has moved from preliminary to more mature in nature making it far more advanced relative to the two other mechanisms. Transactive memory has potential utility for the cognitive domain, especially since it provides a means to address the notion of "compatible but different" knowledge at the team level. However, we need research that gets the concept 
out of the laboratory, into larger teams, and into meaningful work contexts to better gauge its potential. Finally, team learning should be regarded as a construct that is still at an early stage of conceptualization, definition, and development. Key issues include the need to clearly conceptualize the construct, develop measures to assess it directly, and distinguish it from individual learning and performance. In addition, team learning needs to be distinguished from the other cognitive mechanisms. Until these issues are addressed, team learning will remain an ambiguous concept.

With respect to affective/motivational process mechanisms, work on collective efficacy has demonstrated promise as a contributor to team effectiveness. Key research issues include levels of analysis concerns in measurement, articulation of the underlying processes by which collective efficacy is formed and has effects, and examination of potential contextual moderators. The latter issue is also relevant to the cohesion-performance relationship. We need to see solid empirical demonstrations that collective mood or group emotion contribute to team effectiveness; currently, much of this work is purely conceptual. Finally, we need to see levels of analysis concerns-both conceptual and methodologicaladdressed in research on team conflict. Team conflict has tended to be assessed via individual level perceptions that are averaged to the team level. What kind of higher-level construct is conflict? Is it shared by all team members, thereby necessitating evaluation of restricted within team variance? Is it a configuration of team member perceptions? If so, an average misspecifies the construct. We think this work is promising but must better attend to basic levels of analysis principles.

As for behavioral mechanisms, research on team coordination needs to focus on issues of levels and time. If we are to conceptualize coordination as patterns of task interaction over time, we need to better distinguish the individual and collective levels and the emergence of team coordination. Recent theoretical work by Marks et al. (2001) provides a theoretical framework and a typology addressing team processes, with coordination as a key mechanism, that will be helpful for conceptualizing this issue. Finally, we regard communication as an enabler of coordination and cooperation processes. Thus, research on the type and amount of communication should be better integrated with an examination of coordination and cooperation to be more revealing of underlying processes.

Many types of interventions have the potential to enhance team processes, but team training is chief among them. There are three overarching issues in regard to team training research: content (what), timing (when), and techniques (how). The key research issue for training content is the extent to which the frameworks for teamwork competencies generalize from action teams to other less complex team types. For timing, the primary concern is sorting out when it is most appropriate to deliver important 
teamwork skills. This necessitates increased integration between the areas of training and team development. Advanced computer technologies and enhanced connectivity are creating a host of new training tools - web based training, distance learning, distributed interactive simulation. Currently, these tools are primarily used as media to deliver content. The key research issue is how to best utilize these tools for good instructional effect. In addition, team training always raises the issue of the target for delivery: individuals or intact teams? Emerging theory has developed principles to guide this decision, but basic research is needed to establish the impact of delivery level on team effectiveness.

Leadership and Motivation. Leadership and motivation are distinct literatures, but conceptually related areas, with many leadership models focused on motivating or influencing member behavior. Both literatures are huge, and yet both literatures have relatively little to say about leading and motivating teams. On the leadership side, the dominant presumption is that leadership effects "average out" across group members. This tends to result in theories that treat the group as an undifferentiated whole, or in theories that focus on individual influence that aggregates to the group level (There are, of course, exceptions). On the motivation side, theories are almost universally targeted at the individual level. What is the meaning and mechanisms of team level motivation?

Both areas would benefit from theory development and research that are explicitly targeted at the team level. For leadership, efforts to further develop and validate the functional roles of team leaders are needed: What do leaders need to do to promote team effectiveness? There is potential to integrate the functional leadership approach with team self-management: How do teams create substitute mechanisms to fulfill leader functional roles? Team self-management research would benefit from additional efforts to map boundary conditions and moderators that influence its effectiveness as a technique.

For motivation, we need to see the development of true team-level theory. There is some limited work that indicates goals and feedback mechanisms operate at both the team and individual levels. This suggests that goal-based motivational theories (e.g., goal-setting, self-regulation) have the potential to be generalized to the team level. Theory and research challenges relate to the development of multilevel theory — relating parallel theoretical mechanisms at different levels - and evaluation - keeping parallel mechanisms empirically distinct so relative contributions can be disentangled. Though challenging, we believe that this would be a profitable point of departure for a team level theory of motivation.

Continuance and Decline. As teams continue to increasingly form the basic building blocks of organizations, concerns will naturally emerge as to how to maintain their effectiveness over time. Remarkably, we know relatively little about the prospects of long-term effectiveness and the factors that 
may enhance or inhibit team longevity. Research on technological innovation in the 1970s suggested that mature teams become more insular, communicate less, and are less innovative than younger teams. However, though suggestive, empirical support is quite limited. We need basic research to examine the effects of group longevity on team processes and effectiveness over the long term.

$\underline{\text { Conclusion }}$

Teams are alive and well and living in organizations. This reality is pushing the field of industrial and organizational psychology to shift from a science and practice that is primarily focused on the individual level—our traditional roots—to a field that encompasses multiple levels: individual, team, and organization. Because teams occupy the intersection of the multilevel perspective, they bridge the gap between the individual and the organizational system as a whole. They become a focal point. They challenge us to attend to the organizational context, team task, levels, and time. They challenge us to develop new theories, new methodologies, new measurement tools, and new applications, not to just attempt to dust off and generalize our current ones. This creates major challenges for many of our field's traditional methods (e.g., selection, appraisal, training), but it also creates opportunities for theoretical innovation and advances in practice. Our field has much to learn and much to do, but we are confident that industrial and organizational psychology is capable of meeting the challenge afforded by the organization of work around teams.

\section{REFERENCES}

Alderfer, C. P. (1977). Group and intergroup relations. In J. R. Hackman \& J. L. Suttle (Eds.), Improving the quality of work life (pp. 227-296). Palisades, CA: Goodyear.

Amason, A. C. (1996). Distinguishing the effects of functional and dysfunctional conflict on strategic decision making: Resolving a paradox for top management teams. Academy of Management Journal, 39. 123-148.

Ancona, D. G. (1990). Outward bound: Strategies for team survival in the organization. Academy of Management Journal, 33, 334-365.

Ancona, D. G., \& Caldwell, D. F. (1992a). Bridging the boundary: External activity and performance in organizational teams. Administrative Science Quarterly, 37, 634-665.

Ancona, D. G., \& Caldwell, D. F. (1992b). Demography and design: Predictors of new product design team performance. Organizational Science, 3, 321-339.

Anderson, N., Cunningham-Snell, N. A., \& Haigh, J. (1996). Induction training as socialization: Current practice and attitudes to evaluation in British organizations. International Journal of Selection and 
Assessment, 4, 169-183.

Anderson, N., \& Thomas, H. D. C. (1996). Work group socialization. In M. A. West (Ed.), Handbook of work group psychology (pp. 423-450). Chichester: John Wiley \& Sons.

Anderson, N., \& West, M. A. (1998). Measuring climate for work group innovation: Development and validation of the team climate inventory. Journal of Organizational Behavior, 19. 235-258.

Argote, L., Gruenfeld, D., \& Naquin, C. (1999). Group learning in organizations. In M. E. Turner (Ed.), Groups at work: Advances in theory and research. Mahwah, NJ: LEA.

Argote, L., Insko, C. A., Yovetich, N., \& Romero, A. A. (1995). Group learning curves: The effects of turnover and task complexity on group performance. Journal of Applied Social Psychology, 25, $512-$ 529.

Argote, L., \& McGrath, J. E. (1993). Group processes in organizations. Continuity and change. In C. L. Cooper \& I. T. Robertson (Eds.), International review of industrial and organizational psychology (Vol. 8, pp. 333-389). New York: John Wiley \& Sons.

Arrow, H. (1998). Standing out and fitting in: Composition effects on newcomer socialization. In D. H. Gruenfeld (Ed.), Composition. Research on managing groups and teams (Vol. 1, pp. 59-80). Stamford, CT: JAI Press.

Bandura, A. (1986). Social foundations of thought and action. Englewood Cliffs, NJ: Prentice Hall. Bandura, A. (1997). Self-efficacy: The exercise of control. New York: Freeman.

Bantel, K. A. (1994). Strategic planning openness: The role of top team demography. Group and Organization Management, 19, 406-424.

Barrick, M. R., Stewart, G. L., Neubert, J. M., \& Mount, M. K. (1998). Relating member ability and personality to work-team processes and team effectiveness. Journal of Applied Psychology, 83, 377-391.

Barry, B., \& Stewart, G. L. (1997). Composition, process, and performance in self-managed groups: The role of personality. Journal of Applied Psychology, 82, 62-78.

Barsade, S. G. (1998). The ripple effect: Emotional contagion in groups. Working paper.

Barsade, S. G., \& Gibson, D. E. (1998). Group emotion: A view from top and bottom. In D. H. Gruenfeld and Colleagues (Eds.), Composition. Research on managing groups and teams (Vol. 1, pp. 81102). Stamford, CT: JAI Press.

Barsade, S. G., Ward, A., Turner, J., \& Sonnenfeld, J. (1998). To your heart's content: Affective diversity in top management teams. Working paper.

Bass, B. M. (1981). Stogdill's handbook of leadership. New York: Free Press. 
Bell, B. S., \& Kozlowski, S. W. J. (in press). A typology of virtual teams: Implications for effective leadership. Group and Organization Management.

Bettenhausen, K. L. (1991). Five years of group research: What we have learned and what needs to be addressed. Journal of Management, 17, 345-381.

Bettenhausen, K. L., \& Murnighan, J. K. (1985). The emergence of norms in competitive decisionmaking groups. Administrative Science Quarterly, 30, 350-372.

Blickensderfer, E., Cannon-Bowers, J. A., \& Salas, E. (1997). Theoretical bases for team selfcorrections: Fostering shared mental models. In M. M. Beyerlein \& D. A. Johnson (Eds.), Advances in interdisciplinary studies of work teams (Vol. 4, pp. 249-279). Greenwich, CT: JAI Press.

Brannick, M. T., Roach, R. M., \& Salas, E. (1993). Understanding team performance: A multimethod study. Human Performance, 6, 287-308.

Brannick, M. T., Salas, E., \& Prince, C. (Eds.). (1997). Team performance assessment and measurement: Theory, methods, and applications. Mahwah, NJ: LEA.

Brown, K. G., \& Kozlowski, S. W. J. (2000). The dispersion model: Beyond a dichotomous conceptualization of emergent constructs. Working paper.

Campion, M. A., Medsker, G. J., \& Higgs, A. C. (1993). Relations between work group characteristics and effectiveness: Implications for designing effective work groups. Personnel Psychology, 46, 823-850.

Cannon, M., \& Edmondson, A. (2000). Confronting failure: Antecedents and consequences of shared learning-oriented beliefs in organizational work groups. Paper presented at the annual meeting of the Academy of Management Conference, Toronto, ON.

Cannon-Bowers, J. A., \& Salas, E. (1997). A framework for developing team performance measures in training. In M. T. Brannick, E. Salas, C. Prince (Eds.), Team performance assessment and measurement: Theory, methods, and applications (pp. 45-62). Mahwah, NJ: LEA.

Cannon-Bowers, J. A., \& Salas, E. (Eds.). (1998). Making decisions under stress: Implications for individual and team training. Washington, DC: APA.

Cannon-Bowers, J. A., Salas, E., \& Blickensderfer, E. L. (1998). Making fine distinctions among team constructs: Worthy endeavor or "Crewel" and unusual punishment? In R. Klimoski (Chair), When is a work team a crew and does it matter? Symposium presented at the $13^{\text {th }}$ annual conference of the Society for Industrial and Organizational Psychology, Dallas, TX.

Cannon-Bowers, J. A., Salas, E., \& Converse, S. A. (1993). Shared mental models in expert team 
decision making. In N. J. Castellan (Ed.), Individual and group decision making (pp. 221-246). Hillsdale, NJ: LEA.

Cannon-Bowers, J. A., Tannenbaum, S. I., Salas, E., \& Volpe, C. E. (1995). Defining team competencies and establishing team training requirements. In R. Guzzo \& E. Salas (Eds.), Team effectiveness and decision making in organizations (pp. 333-380). San Francisco: Jossey-Bass.

Caple, R. B. (1978). The sequential stages of group development. Small Group Behavior, 9, 470-476. Cascio, W. (2000). Managing a virtual workplace. Academy of Management Executive, 14, 81-90.

Chan, D. (1998). Functional relations among constructs in the same content domain at different levels of analysis: A typology of composition models. Journal of Applied Psychology, 83, 234-246.

Chang, A., Bordia, P., \& Duck, J. (in press). Punctuated equilibrium and linear progression: Toward a new understanding of group development. Academy of Management Journal.

Chao, G. T. (2000). Levels issues in cultural psychology research. In K. J. Klein \& S. W. J. Kozlowski (Eds.), Multilevel theory, research and methods in organizations. San Francisco, CA: JosseyBass.

Chao, G. T., Kozlowski, S. W. J., Major, D. A., \& Gardner, P. (1994a). The effects of individual and contextual factors on organizational socialization and outcomes. Presented at the 9th Annual Conference of the Society for Industrial and Organizational Psychology, Nashville, TN.

Chao, G. T., O’Leary-Kelly, A. M., Wolf, S., Klein, H. J., \& Gardner, P. D. (1994b). Organizational socialization: Its content and consequences. Journal of Applied Psychology, 79, 730-743.

Cohen, S. G., \& Bailey, D. E. (1997). What makes teams work: Group effectiveness research from the shop floor to the executive suite. Journal of Management, 23, 239-290.

Cohen, S. G., \& Ledford, G. E., Jr. (1994). The effectiveness of self-managing teams: A quasiexperiment. Human Relations, 47, 13-43.

Cohen, S. G., Ledford, G. E., \& Spreitzer, G. M. (1996). A predictive model of self-managing work team effectiveness. Human Relations, 49, 643-676.

Coovert, M. D., Campbell, G. E., Cannon-Bowers, J. A., \& Salas, E. (1995). A methodology for a team performance measurement system. Paper presented at the $10^{\text {th }}$ Annual Conference of the Society for Industrial and Organizational Psychology, Orlando, FL.

Dansereau, F., Graen, G., \& Haga, W. J. (1975). A vertical dyad linkage approach to leadership within formal organizations: A longitudinal investigation of the role making process. Organizational 
Behavior and Human Performance, 13, 46-78.

DeMatteo, J. S., Eby, L. T., \& Sundstrom, E. (1998). Team-based rewards: Current empirical evidence and directions for future research. In L. L. Cummings \& B. Staw (Eds.), Research in organizational behavior (Vol. 20, pp. 141-183). Greenwich, CT: JAI Press.

DeShon, R. P., Kozlowski, S. W. J., Schmidt, A. M., Wiechmann, D., \& Milner, K. A. (2001). Developing team adaptability: Shifting regulatory focus across levels. Presented at the $16^{\text {th }}$ Annual Conference of the Society for Industrial and Organizational Psychology, San Diego, CA.

DeShon, R. P., Kozlowski, S. W. J., Wiechmann, D., Milner, K. R., Davis, C. A., \& Schmidt, A. M. (April, 2000). Training and developing adaptive performance in teams and individuals. Presented at the 15th Annual Conference of the Society for Industrial and Organizational Psychology, New Orleans, LA.

Devine, D. J., \& Phillips, J. L. (2000). Do smarter teams do better? A meta-analysis of team-level cognitive ability and team performance. Presented at the $15^{\text {th }}$ Annual Conference of the Society for Industrial and Organizational Psychology, New Orleans, LA.

Driskell, J. E., Hogan, R., \& Salas, E. (1987). Personality and group performance. In C. Hendrick (Ed.), Group processes and intergroup relations (pp. 91-112). Newbury Park, CA: Sage.

Early, P. C., \& Erez, M. (Eds.). (1997). New perspectives on international industrial/organizational psychology. San Francisco: The New Lexington Press.

Edmonson, A. C. (1999). Psychological safety and learning behavior in work teams. Administrative Science Quarterly, 44, 350-383.

Eisenhardt, K. M., \& Schoonhoven, C. B. (1990). Organizational growth: Linking founding team strategy, environment, and growth among U.S. semi-conductor ventures, 1978-1988. Administrative Science Quarterly, 35, 484-503.

Ellis, A., Bell, B. S., \& Ployhart, R. E. (2000, April). Team training: An application of Stevens and Campion's teamwork KSA's. Presented at the $15^{\text {th }}$ Annual Conference of the Society for Industrial and Organizational Psychology, New Orleans, LA.

Erez, M., \& Somech, A. (1996). Is group productivity loss the rule or the exception? Effects of culture and group-based motivation. Academy of Management Journal, 39, 1513-1537.

Evans, C. R., \& Dion, K. L. (1991). Group cohesion and performance: A meta-analysis. Small Group Research, 22, 175-186.

Evans, C. R., \& Jarvis, P. A. (1980). Group cohesion: A review and re-evaluation. Small Group Behavior, 11, 359-370. 
Feltz, D. L., \& Lirgg, C. D. (1998). Perceived team and player efficacy in hockey. Journal of Applied Psychology, 83, 557-564.

Festinger, L. (1950). Informal social communication. Psychological Review, 57, 271-282.

Fiedler, F. E. (1989). The effective utilization of intellectual abilities and job-relevant knowledge in group performance: Cognitive resource theory and an agenda for the future. Applied Psychology: An International Review, 38, 289-304.

Finkelstein, S., \& Hambrick, D. C. (1990). Top management team tenure and organizational outcomes: The moderating role of managerial discretion. Administrative Science Quarterly, 35, 484-503.

Fleishman, E. A., Mumford, M. D., Zaccaro, S. J., Levin, K. Y, Korotkin, A. L., \& Hein, M. B. (1991). Taxonomic efforts in the description of leader behavior: A synthesis and functional interpretation. Leadership Quarterly, 2(4), 245-287.

Fleishman, E. A., \& Zaccaro, W. J. (1992). Toward a taxonomy of team performance functions. In R. W. Swezey \& E. Salas (Eds.), Teams: Their training and performance (pp. 31-56). Norwood, NJ: Ablex.

Foushee, C. H., Manos, K. L. (1981). Information transfer within the cockpit: Problems in intracockpit communications. In C. E. Billings \& E. S. Cheaney (Eds.), Information transfer problems in the aviation system. NASA Technical Paper 1875. Moffett Field, CA: NASA.

Gersick, C. J. G. (1988). Time and transition in work teams: Toward a new model of group development. Academy of Management Journal, 31, 9-41.

Gersick, C. J. (1989). Marking time: Predictable transitions in task groups. Academy of Management Journal, 32, 274-309.

Gibson, C. B. (1999). Do they do what they believe the can? Group efficacy and group effectiveness across tasks and cultures. Academy of Management Journal, 42, 138-152.

Gist, M. E. (1987). Self-efficacy: Implications for organizational behavior and human resource management. Academy of Management Review, 17, 183-211.

Gladstein, D. L. (1984). Groups in context: A model of task group effectiveness. Administrative Science Quarterly, 29, 499-517.

Glickman, A. S., Zimmer, S., Montero, R. C., Guerette, P. J., Campbell, W. J., Morgan, B. B., \& Salas, E. (1987). The evolution of teamwork skills: An empirical assessment with implications for training (Tech. Rep. TR-87-016). Orlando, FL: Naval Training Systems Center.

González-Romá, V., Peiró, J. M., \& Tordera, N. (in press). An examination of the antecedents and moderator influences of climate strength. Journal of Applied Psychology. 
Goodman, P. S., Ravlin, E., \& Schminke, M. (1987). Understanding groups in organizations. In L. L. Cummings \& B. M. Staw (Eds.), Research in organizational behavior (vol. 9, pp. 121-173). Greenwich, CT: JAI Press.

Greene, C. N. (1989). Cohesion and productivity in work groups. Small Group Behavior, 20, 70-86.

Gross, N., \& Martin, W. E. (1952). On group cohesiveness. American Journal of Sociology, 57, 546554.

Guastello, S. J., \& Guastello, D. D. (1998). Origins of coordination and team effectiveness: A perspective from game theory and nonlinear dynamics. Journal of Applied Psychology, 83, 423-437.

Gully, S. M. (2000). Work team research: Recent findings and future trends. In M. Beyerlein (Ed.), Work teams: Past. present. and future (pp. 25-44). The Netherlands: Kluwer Academic Publishers.

Gully, S. M., Devine, D. J., \& Whitney, D. J. (1995). A meta-analysis of cohesion and performance: Effects of levels of analysis and task interdependence. Small Group Research, 26, 497-520.

Gully, S. M., Joshi, A., \& Incalcaterra, K. A. (2001, April). A meta-analytic investigation of the relationships among team-efficacy, self-efficacy, and performance. Presented at the $16^{\text {th }}$ Annual Conference of the Society for Industrial and Organizational Psychology, San Diego, CA.

Guzzo, R. A., \& Dickson, M. W. (1996). Teams in organization: Recent research on performance and effectiveness. Annual Review of Psychology, 47, 307-338.

Guzzo, R. A., \& Shea, G. P. (1992). Group performance and intergroup relations in organizations. In M. D. Dunnette \& L. M. Hough (Eds.), Handbook of industrial and organizational psychology ( $2^{\text {nd }}$ ed., vol. 3, pp. 269-313). Palo Alto, CA: Consulting Psychologist Press.

Guzzo, R. A., Yost, P. R., Campbell, R. J., \& Shea, G. P. (1993). Potency in groups: Articulating a construct. British Journal of Social Psychology, 32, 87-106.

Hackman, J. R. (1986). The psychology of self-management in organizations. In M. S. Pollack \& R. O. Perlogg (Eds.), Psychology and work: Productivity change and employment (pp. 85-136). Washington, DC: American Psychological Association.

Hackman, J. R. (1987). The design of work teams. In J. Lorsch (Ed.), Handbook of organizational behavior (pp. 315-342). New York: Prentice Hall.

Hackman, J. R. (1992). Group influences on individuals in organizations. In M. D. Dunnette \& L. M. Hough (Eds.), Handbook of industrial and organizational psychology (Vol. 3, pp. 199-267).

Hackman, J. R., \& Vidmar, N. (1970). Effects of size and task type on group performance and member reactions. Sociometry, 33, 37-54. 
Hackman, J. R., \& Walton, R. E. (1986). Leading groups in organizations. In P. S. Goodman \& Associates (Eds.), Designing effective work groups. San Francisco: Jossey-Bass.

Haleblian, J., \& Finkelstein, S. (1993). Top management team size, CEO dominance, and firm performance: The moderating roles of environmental turbulence and discretion. Academy of Management Journal, $36,844-863$.

Hambrick, D. C. (1995). Fragmentation and other problems CEOs have with their top management teams. California Management Review, 37, 110-127.

Hambrick, D. C., \& Mason, P. A. (1984). Upper echelons: The organization as a reflection of its top managers. Academy of Management Review, 9, 193-206.

Heslin, R. (1964). Predicting group task effectiveness from member characteristics. Psychological Bulletin, 62, 248-256.

Hill, G. W. (1982). Group versus individual performance: Are N + 1 heads better than one? Psychological Bulletin, 91, 517-539.

Hodges, L., \& Carron, A. V. (1992). Collective efficacy and group performance. International Journal of Sport Psychology, 23, 48-59.

Hofmann, D. A., \& Stetzer, A. (1996). A cross-level investigation of factors influencing unsafe behaviors and accidents. Personnel Psychology, 49, 307-339.

Hollenbeck, J. R., Colquitt, J. A., Ilgen, D. R., LePine, J. A., \& Hedlund, J. (1998). Accuracy decomposition and team decision making: Testing theoretical boundary conditions. Journal of Applied Psychology, 83, 494-500.

Hollenbeck, J. R., Ilgen, D. R., Sego, D. J., Hedlund, J., Major, D. A., \& Phillips, J. (1995). Multilevel theory of team decision making: Decision performance in teams incorporating distributed expertise. Journal of Applied Psychology, 80, 292-316.

Hollingshead, A. B. (1998a). Retrieval processes in transactive memory systems. Journal of Personality and Social Psychology, 74, 659-671.

Hollingshead, A. B. (1998b). Communication, learning, and retrieval in transactive memory systems. Journal of Experimental Social Psychology, 34, 423-442.

Hyatt, D. E., \& Ruddy, T. M. (1997). An examination of the relationship between work group characteristics and performance: Once more into the breech. Journal of Applied Psychology, 50, 553-585.

Jackson, S. E. (1992a). Consequences of group composition for the interpersonal dynamics of strategic issue processing. In P. Shrivastava, A. Huff, \& J. E. Dutton (Eds.), Advances in strategic 
management (Vol. 8, pp. 345-382). Greenwich, CT: JAI Press.

Jackson, S. E. (1992b). Team composition in organizational settings: Issues in managing an increasingly diverse workforce. In S. Worchel, W. Wood, \& J. Simpson (Eds.), Group process and productivity (pp. 138-173). Newbury Park, CA: Sage.

Jackson, S. E., Brett, J. F., Sessa, V. I., Cooper, D. M., Julin, J. A., \& Peyronnin, K. (1991). Some differences make a difference: Individual dissimilarity and group heterogeneity as correlates of recruitment, promotions, and turnover. Journal of Applied Psychology, 76, 675-689.

Jackson, S. E., \& Joshi, A. (in press). Research on domestic and international diversity in organizations: A merger that works. In N. Anderson, D. S. Ones, H. K. Sinangil, and C. Viswesvaran (Eds.), Handbook of work and organizational psychology. Thousand Oaks, CA: Sage.

Jackson, S. E., May, K. E., \& Whitney, K. (1995). Understanding the dynamics of diversity in decision-making teams. In R. A. Guzzo, E. Salas, \& Associates (Eds.), Team effectiveness and decision making in organizations. San Francisco: Jossey-Bass.

Jehn, K. A. (1995). A multimethod examination of the benefits and detriments of intragroup conflict. Administrative Science Quarterly, 40, 256-282.

Karau, S. J., \& Williams, K. D. (1993). Social loafing: A meta-analytic review and theoretical integration. Journal of Personality and Social Psychology, 65, 681-706.

Katz, R. (1980). Time and work: Toward an integrative perspective. Research in Organizational Behavior, 2, 81-127.

Katz, R. (1982). The effects of group longevity on communication and performance. Administrative Science Quarterly, 27, 81-104.

Katz, R., \& Allen, T. J. (1988). Investigating the not invented here (NIH) syndrome: A look at the performance, tenure, and communication patterns of 50 R\&D project groups. In M. L. Tushman \& W. L. Moore (Eds.), Readings in the management of innovation (pp. 293-309). New York: Ballinger.

Katzenbach, J. R., \& Smith, D. K. (1993). The wisdom of teams: Creating the high performance organization. Boston, MA: Harvard Business School Press.

Kelly, J. R., Futoran, G. C., \& McGrath, J. E. (1990). Capacity and capability: Seven studies of entrainment of task performance rates. Small Group Research, 21, 283-314.

Kerr, N., \& Bruun, S. (1983). The dispensability of member effort and group motivation losses: Freerider effects. Journal of Personality and Social Psychology, 44, 78-94. 
Kirkman, B. L., \& Shapiro, D. L. (2000). Understanding why team members won't share: An examination of factors related to employee receptivity to team-based rewards. Small Group Research, 31. 175-209.

Klimoski, R. J., \& Jones, R. (1995). Suppose we took staffing for effective group decision making seriously? In R. Guzzo and E. Salas (Eds.), Teams and groups (pp. 291-332). San Francisco: Jossey-Bass.

Klimoski, R., \& Mohammed, S. (1994). Team mental model: Construct or metaphor? Journal of Management, 20, 403-437.

Komaki, J. L., Desselles, M L., \& Bowman, E. D. (1989). Definitely not a breeze: Extending an operant model of effective supervision to teams. Journal of Applied Psychology, 74, 522-529.

Kormanski, C., \& Mozenter, A. (1987). A new model of team building: A technology for today and tomorrow. In J. W. Pfeiffer (Ed.), The 1987 annual: Developing human resources (pp. 255-268). San Diego, CA: University Associates.

Kozlowski, S. W. J., Brown, K. G., Weissbein, D. A., Cannon-Bowers, J., \& Salas, E. (2000). A multi-level perspective on training effectiveness: Enhancing horizontal and vertical transfer. In K. J. Klein \& S. W. J. Kozlowski (Eds.), Multilevel theory, research, and methods in organizations (pp. 157-210). San Francisco, CA: Jossey-Bass.

Kozlowski, S. W. J., Gully, S. M., McHugh, P. P., Salas, E., \& Cannon-Bowers, J. A. (1996a). A dynamic theory of leadership and team effectiveness: Developmental and task contingent leader roles. In G. R. Ferris (Ed.), Research in personnel and human resource management (Vol. 14, pp. 253-305). Greenwich, CT: JAI Press.

Kozlowski, S. W. J., Gully, S. M., Nason, E. R., \& Smith, E. M. (1999). Developing adaptive teams: A theory of compilation and performance across levels and time. In D. R. Ilgen \& E. D. Pulakos (Eds.), The changing nature of work performance: Implications for staffing, personnel actions, and development (pp. 240-292). San Francisco: Jossey-Bass.

Kozlowski, S. W. J., Gully, S. M., Salas, E., \& Cannon-Bowers, J. A. (1996b). Team leadership and development: Theory, principles, and guidelines for training leaders and teams. In M. Beyerlein, D. Johnson, \& S. Beyerlein (Eds.), Advances in interdisciplinary studies of work teams: Team leadership (Vol. 3, pp. 251-289).

Kozlowski, S. W. J., \& Klein, K. J. (2000). A multilevel approach to theory and research in organizations: Contextual, temporal, and emergent processes. In K. J. Klein \& S. W. J. Kozlowski (Eds.), Multilevel theory, research, and methods in organizations: Foundations, extensions, and new directions 
(pp. 3-90). San Francisco, CA: Jossey-Bass.

Kozlowski, S. W. J., \& Salas, E. (1997). An organizational systems approach for the implementation and transfer of training. In J. K. Ford, S. W. J. Kozlowski, K. Kraiger, E. Salas, \& M. Teachout (Eds.), Improving training effectiveness in work organizations (pp. 247-287). Mahwah, NJ: LEA.

Kozlowski, S. W .J., Toney, R. J., Mullins, M. E., Weissbein, D. A., Brown, K. G., \& Bell, B. S. (2001). Developing adaptability: A theory for the design of integrated-embedded training systems. In E. Salas (Ed.), Advances in human performance and cognitive engineering research (Vol. 1, pp. 59-123). Amsterdam: JAI/Elsevier Science.

Lantané, B, Williams, K., \& Harkin, S. (1979). Many hands make light the work: The causes and consequences of social loafing. Journal of Personality and Social Psychology, 37. 822-832.

Lau, D. C., \& Murnighan, J. K. (1998). Demographic diversity and faultlines: The compositional dynamics of organizational groups. Academy of Management Review, 23, 325-340.

Lawler, E. E. (1986). High involvement management. San Francisco: Jossey-Bass.

Lawler, E. E., Mohrman, S. A., \& Ledford, G. E. (1992). Employee involvement and total quality management: Practices and results in Fortune 1000 companies. San Francisco: Jossey-Bass.

LePine, J. A., Colquitt, J. A., \& Erez, A. (2000). Adaptability to changing task contexts: Effects of general cognitive ability, conscientiousness, and openness to experience. Personnel Psychology, 53. 563593.

LePine, J. A., Hollenbeck, J. R., Ilgen, D. R., \& Hedlund, J. (1997). Effects of individual differences on the performance of hierarchical decision-making teams: Much more than g. Journal of Applied Psychology, 82, 803-811.

Levine, J. M., \& Moreland, R. L. (1990). Progress in small group research. Annual Review of Psychology, 41, 585-634.

Lewis, K. (2000). Is performance all in their minds? The impact of transactive memory on knowledge-worker team performance. Paper presented at the annual Meeting of the Academy of Management, Toronto, ON.

Liang, D. W., Moreland, R., \& Argote, L. (1995). Group versus individual training and group performance: The mediating role of transactive memory. Personality and Social Psychology Bulletin, 21, 384-393.

Lindsley, D. H., Brass, D. J., \& Thomas, J. B. (1995). Efficacy-performance spirals: A multilevel perspective. Academy of Management Review, 20, 645-678. 
Lott, A. J., \& Lott, B. E. (1965). Group cohesiveness as interpersonal attraction: A review of relationships with antecedent and consequent variables. Psychological Bulletin, 64, 259-309.

Louis, M. R., Posner, B. Z., \& Powell, G. N. (1983). The availability and helpfulness of socialization practices. Personnel Psychology, 36, 857-866.

Major, D. A., Kozlowski, S. W. J., Chao, G. T., \& Gardner, P. D. (1995). Newcomer expectations and early socialization outcomes: The moderating effect of role development factors. Journal of Applied Psychology, 80, 418-431.

Manz, C. C. (1992). Self-leading work teams: Moving beyond self-management myths. Human Relations, 45, 1119-1140.

Manz, C. C., \& Sims, H. P., Jr. (1987). Leading workers to lead themselves: The external leadership of self-managing work teams. Administrative Science Quarterly, 32, 106-128.

Marks, M. A., Mathieu, J. E., \& Zaccaro, S. J. (2001). A temporally based framework and taxonomy of team processes. Academy of Management Review, 26, 356-376.

Marks, M. A., Zaccaro, S. J., \& Mathieu, J. E. (2000). Performance implications of leader briefings and team interaction training for team adaptation to novel environments. Journal of Applied Psychology, 85, 971-986.

Martz, W. B., Jr., Vogel, R. R., \& Nunamaker, J. F., Jr. (1992). Electronic meeting systems: Results from the field. Decision Support Systems, 8, 141-158.

Mathieu, J. E., Heffner, T. S., Goodwin, G. F., Salas, E., \& Cannon-Bowers, J. A. (2000). The influence of shared mental models on team process and performance. Journal of Applied Psychology, 85, 273-283.

Matsui, T., Kakuyama, T., \& Onglatco, L. U. (1987). The effects of goals and feedback on performance in groups. Journal of Applied Psychology, 72, 407-415.

McCall, M. W., Jr., Morrison, A. M., \& Hannan, R. L. (1978). Studies of managerial work: Results and methods (Tech Rep. No. 9). Greensboro, NC: Center for Creative Leadership.

McClough, A., \& Rogelberg, S. (1998). An exploration of Stevens and Campion's Teamwork KSA

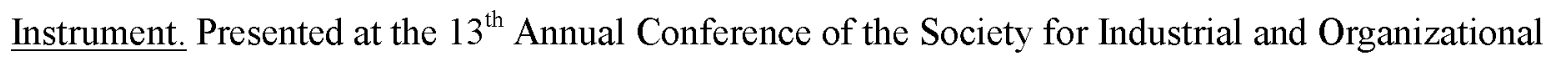
Psychology, Dallas, TX.

McGrath, J. E. (1962). Leadership behavior: Some requirements for leadership training. Washington, DC: U.S. Civil Service Commission.

McGrath, J. E. (1964). Social Psychology: A brief introduction. New York: Holt, Rinehart, \& 
Winston.

McGrath, J. E. (1984). Groups: Interaction and performance. Englewood Cliffs, NJ: Prentice-Hall.

McGrath, J. E. (1990). Time matters in groups. In J. Galegher, R. Krout, \& C. C. Egido (Eds.), Intellectual teamwork (pp. 23-61). Hillsdale, NJ: Lawrence Earlbaum Associates.

McGrath, J. E. (1991). Time, interaction, and performance (TIP): A theory of groups. Small Group Research, 22, 147-174.

McGrath, J. E. (1997). Small group research, that once and future field: An interpretation of the past with an eye toward the future. Group Dynamics, 1, 7-27.

McGrath, J. E., \& Hollingshead, A. B. (1994). Groups interacting with technology. Thousand Oaks, CA: Sage Publications.

Minionis, D. P., Zaccaro, S. J., \& Perez, R. (1995). Shared mental models, team coordination, and team performance. Presented at the 10th Annual Meeting of the Society for Industrial and Organizational Psychology, Orlando, FL.

Mitchell, T. R., \& Silver, W. S. (1990). Individual and group goals when workers are interdependent: Effects on task strategies and performance. Journal of Applied Psychology, 75, 185-193.

Mohammed, S., \& Dumville, B. C . (2001). Team mental models in a team knowledge framework: Expanding theory and measurement across disciplinary boundaries. Journal of Organizational Behavior. 22, 89-106.

Moreland, R. L. (2000). Transactive memory: Learning who knows what in work groups and organizations. In L. Thompson, D. Messick, \& J. Levine (Eds.), Shared cognition in organizations: The management of knowledge (pp. 3-31). Mahwah, NJ: Erlbaum.

Moreland, R. L., Argote, L., \& Krishnan, R. (1998). Training people to work in groups. In R. S. Tindale \& Colleagues (Eds.), Theory and research on small groups (pp. 37-60). New York: Plenum Press.

Moreland, R. L., \& Levine, J. M. (1982). Socialization in small groups: Temporal changes in individual-group relations. In L. Berkowitz (Ed.), Advances in experimental social psychology (Vol. 15, pp. 137-192). New York: Academic Press.

Moreland, R. L., \& Levine, J. M. (1989). Newcomers and oldtimers in small groups. In P. B. Paulus (Ed.), Psychology of group influence ( $2^{\text {nd }}$ ed., pp. 143-186). Hillsdale, NJ: LEA.

Moreland, R. L., \& Levine, J. M. (1992). The composition of small groups. In E. J. Lawler, B. Markovsky, C. Ridgeway, \& H. A. Walker (Eds.), Advances in group processes (Vol. 9, pp. 237-280). Creenwich, CT: JAI Press. 
Morgan, B. B., Salas, E., \& Glickman, A. S. (1993). An analysis of team evolution and maturation. Journal of General Psychology, 120, 277-291.

Mullen, B., \& Copper, C. (1994). The relation between group cohesiveness and performance: An integration. Psychological Bulletin, 115(2), 210-227.

Neck, C. P., Stewart, G. L., \& Manz, C. C. (1996). Self-leaders within self-leading teams: Toward an optimal equilibrium. In M. Beyerlein, D. A. Johnson, \& S. Beyerlein (Eds.), Advances in interdisciplinary studies of work teams: Team leadership (Vol. 3, pp. 43-65). Greenwich, CT: JAI Press.

Neuman, G. A., Wagner, S. H., \& Christiansen, N. D. (1999). The relationship between work-team personality composition and the job performance in teams. Group and Organization Management, 24, 2845 .

Neuman, G. A., \& Wright, J. (1999). Team effectiveness: Beyond skills and cognitive ability. Journal of Applied Psychology, 84, 376-389.

Nieva, V. F., Fleishman, E. A., \& Reick, A. (1985). Team dimensions: Their identity, their measurement, and their relationships (Research Note 85-12). Washington, DC: U. S. Army, Research Institute for the Behavioral and Social Sciences.

Ostroff, C., \& Kozlowski, S. W. J. (1992). Organizational socialization as a learning process: The role of information acquisition. Personnel Psychology, 45, 849-874.

Paskevich, D. M., Brawley, L. R., Dorsch, K. D., \& Widmeyer, W. N. (1999). Relationship between collective efficacy and team cohesion: Conceptual and measurement issues. Group Dynamics, 3, 210-222.

Pelled, L. H., Eisenhardt, K. M., \& Xin, K. R. (1999). Exploring the black box: An analysis of work group diversity, conflict, and performance. Administrative Science Quarterly, 44, 1-28.

Pelz, D. C., \& Andrews, F. M. (1966). Scientists in organizations: Productive climates for research and development. Ann Arbor, MI: Institute for Social Research, The University of Michigan.

Phillips, J. M. (1999). Antecedents of leader utilization of staff input in decision-making teams. Organizational Behavior and Human Decision Processes, 77, 215-242.

Pinto, M. B., \& Pinto, J. K. (1990). Project team communication and cross-functional cooperation in new program development. Journal of Product Innovation Management, 7, 200-212.

Pritchard, R. D., Jones, S. D., Roth, P. L., Stuebing, K. K., \& Ekeberg, S. E. (1998). Effects of group feedback, goal setting, and incentives on organizational productivity. Journal of Applied Psychology, 73 , 337-358.

Saavedra, R., Earley, P. C., \& Van Dyne, L. (1993). Complex interdependence in task-performing 
groups. Journal of Applied Psychology, 78, 61-72.

Salas, E., Dickinson, T. L., Converse, S. A., \& Tannenbaum, S. I. (1992). Toward an understanding of team performance and training. In R. W. Swezey \& E. Salas (Eds.), Teams: Their training and performance (pp. 3-29). Norwood, NJ: Ablex.

Salas, E., Fowlkes, J., Stout, R. J., Prince, C., \& Milanovich, D. M. (1999a). Does CRM training enhance teamwork skills in the cockpit? Two evaluation studies. Human Factors, 41, 326-343.

Salas, E., Prince, C., Bowers, C. A., Stout, R., Oser, R. L., \& Cannon-Bowers, J. A. (1999b). A methodology to enhance crew resource management training. Human Factors, 41, 161-172.

Salas, E., Rozell, D., Driskell, J. D., \& Mullen, B. (1999c). The effect of team building on performance: An integration. Small Group Research, 30, 309-329.

Scharf, A. (1989). How to change seven rowdy people. Industrial Management, 31, 20-22.

Schneider, B. (1987). The people make the place. Personnel Psychology, 40, 437-453.

Schneider, B, Smith, D. B., \& Sipe, W. P. (2000). Personnel selection psychology: Multi-level considerations. In K. J. Klein \& S. W. J. Kozlowski (Eds.), Multilevel theory, research, and methods in organizations. San Francisco, CA: Jossey-Bass.

Seashore, S. E. (1954). Group cohesiveness in the industrial work group. Ann Arbor, MI: Institute for Social Research.

Seers, A., Petty, M. M., \& Cashman, J. F. (1995). Team-member exchange under team and traditional management: A naturally occurring quasi-experiment. Group \& Organization Management, 20, 18-38.

Shaw, M. E. (1976). Group dynamics. New York: McGraw-Hill.

Shea, G. P., \& Guzzo, R. A. (1987). Groups as human resources. In K. M. Rowland \& G. R. Ferris (Eds.), Research in personnel and human resource management (Vol. 5, pp. 323-356). Greenwich, CT: JAI Press.

Shepard, H. A. (1956). Creativity in R/D teams. Research in Engineering, October, 10-13.

Sheppard, J. A. (1993). Productivity loss in performance groups: A motivation analysis. Psychological Bulletin, 113, 67-81.

Sheremata, W. A. (2000). Centrifugal and centripetal forces in radical new product development under time pressure. Academy of Management Review, 25, 389-408.

Simons, T., Pelled, L. H., \& Smith, K. A. (1999). Making use of difference: Diversity, debate, and decision comprehensiveness in top management teams. Academy of Management Journal, 6, 662-673.

Simons, T. L., \& Peterson, R. S. (2000). Task conflict and relationship conflict in top management 
teams: The pivotal role of intragroup trust. Journal of Applied Psychology, 85, 102-111.

Smith, K. G., Smith, K. A., Olian, J. D., Smis, H. P., Jr., O’Bannon, D. P., \& Scully, J. A. (1994). Top management team demography and process: The role of social integration and communication. Administrative Science Quarterly, 39, 412-438.

Smith-Jentsch, K. A., Milanovich, D. M., Reynolds, A. M., \& Hall, S. M. (1999). Fostering the development of shared teamwork knowledge structure through computer-based instruction. Presented at the $14^{\text {th }}$ Annual Conference of the Society for Industrial and Organizational Psychology, Atlanta, GA.

Smith-Jentsch, K. A., Zeisig, R. L., Acton, B., \& McPherson, J. A. (1998). Team dimensional training: A strategy for guided team self-correction. In J. A. Cannon-Bowers \& E. Salas (Eds.), Making decisions under stress: Implications for individual and team training (pp. 271-297). Washington, DC: APA Press.

Smolek, J., Hoffman, D., \& Moran, L. (1999). Organizing teams for success. In E. Sundstrom (Ed.), Supporting work team effectiveness (pp. 24-62). San Francisco: Jossey-Bass.

Staw, B. M., Sutton, R. I., \& Pelled, L. H. (1994). Employee positive emotion and favorable outcomes at the workplace. Organization Science, 5, 51-71.

Steiner, I. D. (1972). Group process and productivity. New York: Academic Press.

Stevens, M. J., \& Campion, M. A. (1994). The knowledge, skill, and ability requirements for teamwork: Implications for human resource management. Journal of Management, 20, 503-530.

Stewart, G. L., \& Barrick, M. R. (2000). Team structure and performance: Assessing the mediating role of intrateam process and the moderating role of task type. Academy of Management Journal, 43, 135148.

Stewart, G. L., \& Barrick, M. R. (in press). Lessons learned from the person-situation debate: A review and research agenda. In D. B. Smith \& B. Schneider (Eds.), Personality and Organizations. Mahwah, NJ: Erlbaum.

Stewart, G. L., \& Manz, C. C. (1995). Leadership for self-managing work teams: A typology and integrative model. Human Relations, 48, 347-370.

Stout, R. J., Cannon-Bowers, J. A., Salas, E., \& Milanovich, D. M. (1999). Planning, shared mental models, and coordinated performance: An empirical link is established. Human Factors, 41, 61-71.

Stout, R. J., Salas, E., \& Carson, R. (1994). Individual task proficiency and team process behavior: What's important for team functioning. Military Psychology, 6, 177-192.

Sundstrom, E., DeMeuse, K. P., \& Futrell, D. (1990). Work teams: Applications and effectiveness. 
American Psychologist, 45, 120-133.

Sundstrom, E., McIntyre, M., Halfhill, T., \& Richards, H. (2000). Work groups from the Hawthorne studies to work teams of the 1990's and beyond. Group Dynamics: Theory, Research, and Practice, 4, 4467.

Swezey, R. W., \& Salas, E. (1992). Guidelines for use in team training development. In R. W. Swezey \& E. Salas (Eds.), Teams: Their training and performance. Norwood, NJ: Ablex.

Tannenbaum, S. I., Beard, R. L., \& Salas, E. (1992). Team building and its influence on team effectiveness: An examination of conceptual and empirical developments. In K. Kelley (Ed.), Issues, theory, and research in industrial/organizational psychology (pp. 117-153). Amsterdam: Elsevier.

Tesluk, P., Kirkman, B. L., \& Cordery, J. L. (2001). Effects of work unit cynicism on efforts to increase self-management in work groups: Implications for implementing high-involvement approaches. Working paper.

Tjosvold, D. (1985). Implications of controversy research for management. Journal of Management, 11. 21-37.

Tuckman, B. W. (1965). Developmental sequence in small groups. Psychological Bulletin, 63, 384399.

Tuckman, B. W., \& Jensen, M. A. C. (1977). Stages of small-group development revisited. Group and Organization Studies, 2, 419-427.

Tziner, A., \& Eden, D. (1985). Effects of crew composition on crew performance: Does the whole equal the sum of its parts? Journal of Applied Psychology, 70, 85-93.

U.S. Department of Labor. (1993). High performance work practices and firm performance. Washington, DC: Office of the American Workplace.

Van De Ven, A. H., Delbecq, A. L., \& Koenig, R. (1976). Determinants of coordination modes within organizations. American Sociological Review, 41, 322-338.

Wageman, R. (1997). Critical success factors for creating superb self-managing teams. Organizational Dynamics, 26, 49-61.

Wageman, R. (1999). Task design, outcome interdependence, and individual differences: Their joint effects on effort in task-performing teams (Commentary on Huguet et al., 1999). Group Dynamics, 3 , $132-137$.

Wagner, J. A. (1995). Studies of individualism-collectivism: Effects on cooperation in groups. Academy of Management Journal, 38, 152-172. 
Waller, M. J. (1999). The timing of adaptive group responses to nonroutine events. Academy of Management Journal, 42, 127-137.

Watson, W. E., Kumar, K., \& Michaelsen, L. K. (1993). Cultural diversity's impact on interaction process and performance: Comparing homogenous and diverse task groups. Academy of Management Journal, 36, 590-602.

Weaver, J. L., Bowers, C. A., Salas, E., \& Cannon-Bowers, J. A. (1997). Motivation in teams. In M. M. Beyerlein \& D. A. Johnson (Eds.), Advances in interdisciplinary studies of work teams (Vol. 4, pp. 167-191). Greenwich, CT: JAI Press.

Wegner, D. M. (1986). Transactive memory: A contemporary analysis of the group mind. In B. Mullen \& G. R. Goethals (Eds.), Theories of group behavior (pp. 185-208). New York: Springer-Verlag.

Wegner, D. M. (1995). A computer network model of human transactive memory. Social Cognition, 13(3), 319-339.

Wegner, D. M., Giuliano, T., \& Hertel, P. (1985). Cognitive interdependence in close relationships. In W. J. Ickes (Ed.), Compatible and incompatible relationships (pp. 253-276). New York: Springer-Verlag.

West, M. A., \& Anderson, N. R. (1996). Innovation in top management teams. Journal of Applied Psychology, 81, 680-693.

Wheelan, S. A. (1994). Group processes: A developmental perspective. Sydney: Allyn and Bacon.

Wiersema, M. F., \& Bantel, K. A. (1992). Top management team demography and corporate strategic change. Academy of Management Journal, 35, 91-121.

Yukl, G., \& Van Fleet, D. D. (1992). Theory and research on leadership in organizations. In M. Dunnette \& L. Hough (eds.), Handbook of I/O psychology (Vol. 3, pp. 147-198). Palo Alto, CA: Consulting Psychologists Press.

Zaccaro, S. J., Blair, V., Peterson, C., \& Zazanis, M. (1995). Collective efficacy. In J. Maddux (Ed.), Self-efficacy, adaptation, and adjustment (pp. 305-328). New York: Plenum.

Zaccaro, S. J., \& Lowe, C. A. (1988). Cohesiveness and performance on an additive task: Evidence for multidimensionality. Journal of Social Psychology, 128(4), 547-558.

Zaccaro, S. J., \& McCoy, M. C. (1988). The effects of task and interpersonal cohesiveness on performance of a disjunctive group task. Journal of Applied Social Psychology, 18, 837-851.

Zajonc, R. B. (1965). Social facilitation. Science, 149, 269-274.

Zalesny, M. D., Salas, E., \& Prince, C. (1995). Conceptual and measurement issues in coordination: Implications for team behavior and performance. In G. R. Ferris (Ed.), Research in personnel and human 
resources management (Vol. 13, pp. 81-115). Greenwich, CT: JAI Press. 